\title{
ESPACIOS ESCOLARES \\ ABANDONADOS, PRÁCTICA \\ DOCENTE Y POLÍTICA \\ EDUCATIVA EN CHIHUAHUA
}

FERNANDO SANDOVAL GUTIÉRREZ

KARLA IVONNE GONZÁLEZ TORRES²

El propósito central de la escuela es

convertir espejos en ventanas.

- Sydney J. Harris

\section{RESUMEN}

1 l final del ciclo escolar 1997-1998 marcó en Chihuahua el inicio del programa de Centros Regionales de Educación Integral, y el cierre de decenas de escuelas rurales. El texto presenta los resultados de un trabajo de investigación realizado en las comunidades cercanas a la laguna de Bustillos, que contaban con escuela hasta 1997. Se utilizó la entrevista a profundidad y un proceso analítico basado en la Teoría Fundamentada. Se construyó una narrativa explicativa de la realidad educativa cotidiana en

1 Docente fundador de la División Multidisciplinaria de la UACJ en Cuauhtémoc, Chih.

2 Docente de la División Multidisciplinaria de la UACJ en Cuauhtémoc, Chih.

Los autores deseamos hacer patente nuestro agradecimiento a Cindy Monclova, Karla Jacobo, Evelin Rivera y a Raúl Humberto Castro, estudiantes del programa de Educación de la Universidad Autónoma de Ciudad Juárez en Cuauhtémoc, por su participación en este proyecto como investigadores de campo. De igual manera agradecemos a los informantes de las comunidades de Bustillos, Tres Lagunas, Favela y Baldón por su invaluable colaboración.

Este texto está dedicado al profesor (rural, marginal, urbano, amoroso, severo, ejemplar) Leonel Gutiérrez Medrano. 
las escuelas rurales antes de su cierre, y de cómo esta institución marcó culturalmente a las comunidades que la acogieron.

Palabras clave: educación rural, práctica docente, vida cotidiana escolar.

\begin{abstract}
The end of the 1997-1998 school year marked in Chihuahua the beginning of the Program of Regional Centers of Integral Education, and the closure of dozens of rural schools. The text presents the results of a research work carried out in the communities near the Bustillos lagoon, which had a school until 1997. In-depth interviewing and an analytical process based on Founded Theory was used. An explanatory narrative was built of everyday educational reality in rural schools before its closure, and how this institution culturally marked the communities that welcomed it.
\end{abstract}

Keywords: rural education, teaching practice, daily school life.

\title{
Y EN EL RANCHO SE QUEDÓ LA ESCUELA, CON LAS BANCAS ARRUMBADAS...
}

La escuela pública rural en México es un tema en vías de extinción. No lo es la institución en sí misma - persisten aún miles de centros educativos operando en localidades de menos de 2,000 habitantes desperdigadas por el país-, pero sí lo es el carácter altamente simbólico, político y por supuesto educativo que tuvo esta institución los últimos noventa años. La escuela pública rural se diluye en los desafíos y dinámicas de su pariente rica: la escuela urbana, marcada por el dilatado volumen de sus matrículas, de sus plantas docentes, y por la importancia de su componente político, estratégico para las realidades locales y agregadas. ¿Cuánto tiempo ha pasado desde que escuchamos hablar a los políticos de la escuela rural como elemento importante para la vida nacional 
o estatal? Su presencia es cada vez más diluida, cada vez más opaca.

La escuela rural se desplaza poco a poco del imaginario colectivo, empujada hacia las sombras por los procesos de migración del rancho hacia las ciudades, iniciados en la década de los veinte del siglo pasado, y acelerados en la posguerra, por la recomposición demográfica de las realidades en las que opera, por las llamadas reformas educativas de los años recientes, por la ignorancia de su importancia histórica.

La escuela rural persiste como un survival aún necesario, pero en franca vía de extinción, cada vez menos frecuente y cada vez más anecdótico. La escuela rural, sin Internet -o sin luz eléctrica siquiera-, con maestros multigrado, es una curiosidad histórica, propia de otros tiempos, ajena a los usos del WhatsApp y de la inmediatez digital.

Sin embargo, tercas, persisten las escuelas rurales. Siguen ahí en medio de los peladeros del desierto en Chihuahua y en México, azotadas por los ventarrones de Semana Santa, o en las laderas terciadas de pinos y pedruscos, o en los calorones espantosos del llano, o escondidas en alguna escorrentía, con sus canalones adornados por los carámbanos de hielo que dejó la última helada, mucho más allá de donde llegan la carretera y la señal del teléfono celular. Ahí están las maestras y maestros unitarios, o bidocentes, en las antiguas casas del maestro, con sus techumbres aullantes de lámina y muros de adobe, lo mismo que las trojes de la escuela, con sus ratas regordetas y felices de tanto comer maíz, al lado de la parcela escolar.

La escuela rural en Chihuahua es un tópico que soporta acercamientos muy diversos. En este texto nos aproximamos a ella a partir de un evento que a mediados de la década de los noventa transformó la realidad de estas instituciones en la dimensión estatal, y con el paso de los años, la nacional. A principios de 1997, el gobierno del estado de Chihuahua anunció el cierre definitivo de las escuelas primarias de las comunidades asentadas en la ribera de la laguna de Bustillos, en el municipio de Cuauhtémoc, para 
concentrar sus matrículas en el primer centro PIRE (Programa de Integración Rural a través de la Educación).

El centro se ubicó en el poblado de Favela. Ahí los edificios de la antigua escuela rural del ejido se remozaron y complementaron con otros nuevos, para recibir en agosto de 1997 a la primera generación de chicos del flamante centro piloto. La escuela ofrecería a sus estudiantes clases de inglés, computación, educación artística, transporte escolar sin costo desde cada comunidad rural, alimentación gratuita para los niños y horario extendido, de ocho de la mañana a las tres de la tarde. Se trataba de una experiencia totalmente innovadora en la concepción de la educación rural, que no contaba con parangón alguno hasta entonces en Chihuahua.

La experiencia en Favela fue el origen del PIRE y posteriormente del programa CREI (Centros Regionales de Educación Integral), como medidas de política pública con finalidades diversas: primero aquellas expresadas en el discurso oficial de la época, centrado en la conveniencia de centralizar a los chicos de comunidades rurales pequeñas en una escuela de mayores dimensiones - de infraestructura, personal y servicios educativos- para garantizar la calidad de la oferta educativa ofrecida mediante la concentración de servicios que eran impensables en las pequeñas escuelas rurales de antaño y darle consecución al objetivo de:

Ofrecer a la niñez del medio una educación que les permita solventar las necesidades más sentidas propias del lugar, dadas sus características; y poder equiparar la educación que se brinda a estos niños con la que se imparte en el medio urbano (Centro piloto PIRE, 2009).

La fundación del PIRE, en otro nivel se explicó por motivos administrativos y políticos, relacionados con el ahorro en el sostenimiento de una sola escuela por encima de varias, y con la necesidad de obtener mecanismos de control político más efectivos de las plantillas de personal docente. Desde la fundación del sistema educativo estatal moderno en 1921, y con especial intensidad luego de la aplicación del llamado Plan Chihuahua en 1958, durante 
la administración de Teófilo Borunda Ortiz, Chihuahua se perló de una constelación amplia de escuelas rurales, establecidas en pequeños asentamientos ejidales, en rancherías indígenas, en poblados minúsculos. La red de escuelas -de los subsistemas estatal y federal- constituyó una de las bases para que los indicadores de alfabetismo ascendieran de manera importante desde 1960, y que la cobertura del servicio educativo en el nivel de primaria se acercara en el lustro reciente a la universalidad. Además, la presencia de estas escuelas rurales marcó de formas complejas y permanentes la cultura y los arreglos simbólicos de los nichos culturales de cada comunidad. La escuela se convirtió en uno de los elementos culturales más importantes para el pueblo o para el rancho, y en la expresión más cercana del Estado Mexicano en la cotidianidad bucólica chihuahuense.

Sin embargo, para 1997 el gobierno estatal encabezado por Francisco Javier Barrio Terrazas -el primer gobernador chihuahuense no proveniente del Partido Revolucionario Institucionalpercibía a la red de escuelas rurales como un tema a resolver. La relación del gobernador Barrio con los maestros no había sido fácil. Desde el inicio de su administración, se planteó el desafío de lo que él llamó la "recuperación de la rectoría en educación" (Sandoval, 2014), a través de un replanteamiento de las relaciones de la administración estatal con las secciones sindicales, históricamente corporativas y orgánicas. El ejercicio del primer gobierno de alternancia, en lo educativo se caracterizó en este sentido por su rispidez, sobre todo con la Sección 42 del Sindicato Nacional de Trabajadores de la Educación (SNTE), con quien vivió el desencuentro más importante en la historia de la educación estatal de los años recientes. La posibilidad de lograr un control más preciso de los centros docentes en lo económico y político hacía mucho sentido a la lógica operativa del gobierno de la entidad.

Dos ciclos escolares después de la apertura del PIRE original abrieron sus puertas los siguientes: uno en La Mesa, municipio de Aldama, y otro más en San Andrés, Rivapalacio, ambos reproduciendo el modelo ensayado en Favela. Los gobiernos estatales que sucedieron al de Francisco Javier Barrio siguieron impulsando la 
creación y operación de estas instituciones educativas, mediante una política sostenida consistente en la reubicación del personal docente que laboraba en las comunidades rurales hacia estos nuevos centros.

La contundencia del apoyo fue de tal magnitud, que el Congreso estatal expidió en 2003 el "Decreto y Reglamento Estatal Para la Instauración, Operación, Sostenimiento y Evaluación de los CREI", que le daba sustento legal a esta figura organizativa. Como resultado de estas experiencias, finalmente en 2007, el gobierno federal arrancó para todo el país el Programa Nacional de Escuelas de Tiempo Completo, inspirado en buena medida en la experiencia del PIRE y de los CREI de Chihuahua, que sirvieron como centros pilotos para lo que ocurriría luego en múltiples regiones rurales en México.

Hoy han pasado ya veintiún años del inicio de este periplo. La experiencia en los CREI ha sido rica y variada, y sus resultados han sido motivo de diversos acercamientos desde la investigación educativa, orientados sobre todo a la revisión de sus indicadores de rendimiento educativo, en busca de las evidencias de que lo dicho por las autoridades educativas del estado a mediados de la década de los noventa, con respecto a su conveniencia para elevar la calidad del servicio educativo y mejorar así la formación de los chicos y chicas que transitan por sus aulas, resultó cierto (Arroyo, Serrano y Alonso, 2011). Con la evidencia de los años pasados, es posible afirmar que los CREI constituyen experiencias atípicas de una forma de educación que no deja de ser rural, con las costumbres y usos de escuelas de pueblo, en las que las ceremonias siguen teniendo importancia cultural, y en donde la escuela aún es un referente simbólico muy importante para la vida comunitaria. Son espacios en los que las relaciones se redefinen a partir del contacto interaccional cotidiano e intenso de los chicos y chicas de las rancherías, y en donde se viven los procesos educativos de maneras nuevas, festivas, complejas.

En la conspicua estela de los CREI quedaron, cada vez más en silencio, las antiguas escuelitas rurales. En muchos casos de una sola aula, sin cerco perimetral, con las ventanas destrozadas, y las 
puertas arrancadas de los marcos, con sus canchas encenagadas, y las astabanderas oxidadas, señalando al cielo como antenas tercas. En la mayor parte de las decenas de comunidades rurales que contaban con escuela rural, los edificios fueron oficialmente destinados a la creación de centros comunitarios, para la oferta de talleres de artes y oficios, y para la celebración de actividades de tipo cultural, sin embargo, la disposición no se acompañó de medidas de política pública ni de financiamiento, por lo que las propias comunidades decidieron por procedimientos locales el destino de los antiguos espacios escolares.

En algunos casos las escuelas permanecen aún cerradas, esperando ser de algún uso, y la llave la tiene doña Esperanza, la de la tienda, que estudió toda su primaria ahí, y que la abre una o dos veces al año para instalar la casilla electoral, o pasa de mano en mano, quedando bajo la responsabilidad del comisario ejidal en turno, o de plano se perdió, y los salones son una cápsula del tiempo en el que las capas de polvo se depositan mansamente sobre el libro de asistencia del ciclo escolar 96-97, y de los viejos libros del rincón de lecturas. En algunas de esas aulas encapsuladas se conservan los archivos de la escuela: verdaderos tesoros para la historia de la educación y para la microhistoria. En otros casos, los más tristes, la escuela ya no existe más: sus techos de machimbre colapsaron, y finalmente las paredes de adobe se convirtieron en tapias erosionadas, desnudas de los esquemas y mapas que alguna vez sostuvieron:

Una de las preguntas básicas es ¿qué utilidad se dio a las escuelas desocupadas? La idea central era que los ejidos o comunidades les dieran un uso adecuado a las instalaciones, mas no siempre fue así y se deterioraron, o bien como en muchos de los casos se convirtieron en bodegas para grano (Loera, 2007).

En la mayoría de los casos es impensable, a casi un cuarto de siglo de su clausura, la idea de reutilizar estos espacios para fines educativos. La mayor parte de estas escuelas rurales que operaron durante cuatro décadas y que formaron a miles y miles de niños 
y niñas chihuahuenses en condiciones de marginación, cerraron sus puertas para no abrirse más. Sin embargo, no hay ranchería en la que no persistan en la memoria los recuerdos de los buenos -y malos- profesores, los festivales escolares, las graduaciones extensas con chile colorado y arroz, los festivales del Día de la Madre, y en la vitrina la fotografía de Dianita el día de su graduación de primaria - la primera y única en su vida-, con su padrino y sus papás, todos muy contentos.

En este texto ofrecemos nuestro acercamiento a la realidad de estos cascarones escolares, que se derrumban mientras escribimos estas líneas. Es nuestro interés contribuir a la reflexión acerca de su devenir y llamar la atención hacia la necesidad de la preservación de sus historias, y del reconocimiento de su aportación a la educación rural chihuahuense. Nuestra pretensión no es llamar la atención hacia los CREI, sino hacia las escuelas que les heredaron sus matrículas a mediados de los noventa.

\section{APUNTE METODOLÓGICO}

Durante la segunda mitad de 2017 iniciamos un proceso de identificación de escuelas rurales abandonadas en la región del primer PIRE, en la zona centro del estado de Chihuahua (mapa 1.1). El área era de nuestro interés justo por la condición de haber sido las primeras incluidas en los mecanismos de cierre de las escuelas tradicionales para dar paso a ser objeto de atención de las nuevas instituciones educativas de las que hemos hablado.

Mapa 1. 1

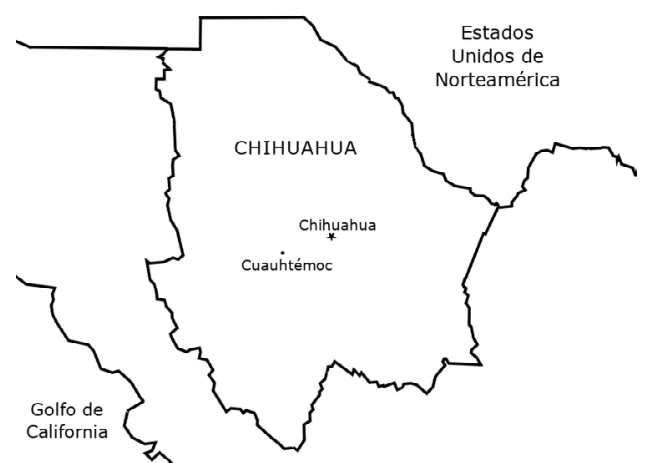


La zona de influencia del PIRE se situó en las cercanías de la localidad de Anáhuac, una de las tres secciones municipales de Cuauhtémoc, el tercer municipio menos marginado del estado y centrado en la producción manzanera y agrícola (Martínez, 1999). La ciudad de Cuauhtémoc se ubica al sur de un cajón geográfico en donde se asienta la laguna de Bustillos, un espejo de agua de $200 \mathrm{~km}^{2}$ y con una capacidad de almacenamiento estimada en 148 millones de $\mathrm{m}^{3}$ (Franco y Alvarez, 2001). La ciudad de Cuauhtémoc se ubica a unos 16 kilómetros de Anáhuac y a 100 de la capital del estado (mapa 1.2).

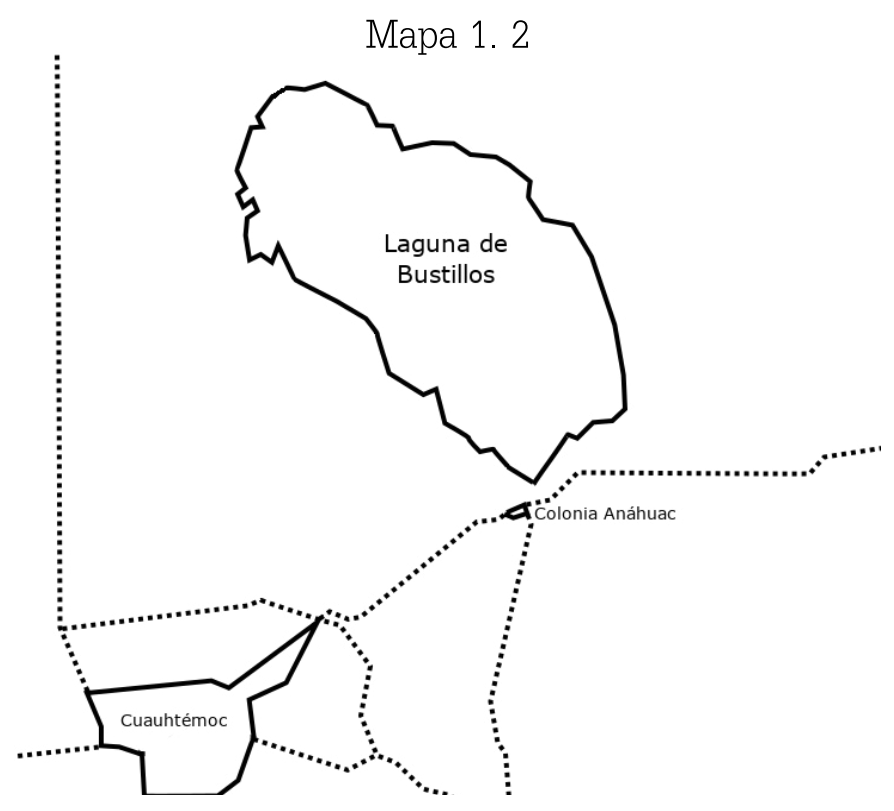

En este contexto geográfico identificamos ocho comunidades rurales que cumplían con los siguientes criterios:

-Fueron cerradas a finales del ciclo escolar 1996-1997

-Sus poblaciones escolares se reasignaron al PIRE en Favela

-Se asientan en los límites de las aguas de la laguna de Bustillos o en el valle que la circunda 
A partir de estas consideraciones fue posible integrar un listado de ocho comunidades, incluyendo a Favela.

Ejido Favela

Centro Calles

Rodrigo M. Quevedo (Baldón)

La Selva

Cuitláhuac

Vista Hermosa

La Noria de Aldana

Tres Lagunas

Bustillos

Favela, Centro Calles, La Selva, Cuitláhuac, y Vista Hermosa se asientan a pocos metros de las aguas de la laguna, mientras que Baldón, La Noria, Tres Lagunas y Bustillos lo hacen en el valle. Todas son comunidades rurales, pertenecientes a los ejidos agrícolas creados en el primer cuarto del siglo pasado (mapa 1.3). En las ocho comunidades la gente practica la agricultura de temporal y la ganadería a pequeña y mediana escala, y se emplean en diversas actividades en las huertas manzaneras particulares que hay en la zona (Gobierno del Estado de Chihuahua, 2016) o viajan a Anáhuac o a Cuauhtémoc para laborar como empleados. Todas estas comunidades contaban con sus escuelas rurales, fundadas a finales de la década de los cincuenta, o en los setenta. En algunas comunidades la escuela contaba además con parcela escolar, que se utilizaba para financiar mejoras a la escuela y para propósitos educativos. Aunque en la década reciente todas estas pequeñas comunidades han sido azotadas por la migración, en todas aún viven personas que pasaron por las aulas de las escuelas rurales, lo que constituyó una posibilidad muy valiosa de obtener información al respecto. 


\section{Mapa 1. 3}

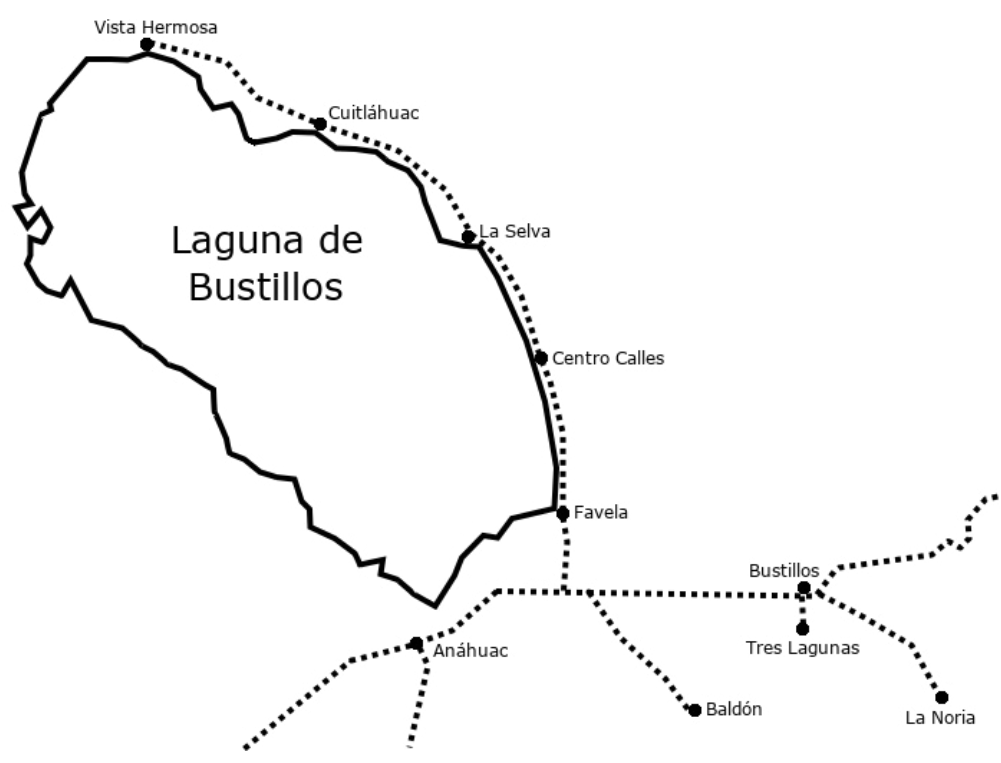

Se realizaron visitas a las comunidades entre febrero y noviembre de 2017. En todos los casos fue posible el ingreso a las antiguas instalaciones de las escuelas (en algunos casos el estado de abandono en el que se encuentran significa que no se conservan los antiguos cercos o bardas que antes las circundaban) para obtener material fotográfico y constatar el estado físico de las instalaciones. En algunas localidades, la llave del candado del cerco perimetral, o de algún salón, es conservada por algún vecino. En otros casos el acceso a las antiguas instalaciones educativas es totalmente libre. Encontramos además que algunos patios escolares son utilizados como terrenos de agostadero.

Los informantes fueron identificados a partir de la presencia directa en las comunidades. Al realizar las visitas a cada una de ellas y mediante el diálogo inicial con las personas en posesión de las llaves de las escuelas, construimos el listado de potenciales participantes. Nos dimos cuenta de que en la mayoría de las rancherías viven aún muchos exalumnos y exalumnas que cursaron la primaria en las escuelas ahora cerradas. Por la época en la que 
se tomó la decisión del cierre, se trata de personas que hoy en día están entre los 25 y los 35 años, que en muchos casos tienen ahora hijos en edad escolar y que recuerdan con claridad sus días en la escuela del rancho. Las entrevistas realizadas en el campo nos permitieron construir una visión agregada con respecto a cómo era la vida cotidiana y la construcción de la cultura escolar, hace veinte años en esos espacios. Para el acopio de la información se preparó un guión de entrevista semiestructurada (Guillén, 1991). Con este instrumento nos encontramos con 12 informantes que se videograbaron (con excepción de dos, que solo nos permitieron registrarlos en audio). Adicionalmente se levantaron registros fotográficos en todas las visitas que realizamos.

Un apunte necesario es comentar que la realización de las primeras entrevistas hizo posible complejizar y matizar nuestra visión acerca de los hechos y eventos estudiados. El diálogo con los informantes hizo posible la emergencia de categorías tempranas de análisis, que posibilitaron reorientar las entrevistas sucesivas. Debido a razones logísticas, el ejercicio de acopio de información mediante entrevistas se limitó a doce. Sin embargo quedaron pendientes acercamientos futuros a la gente en las comunidades de estudio.

Por razones fortuitas, pudimos identificar y trabajar en otras comunidades con escuelas con perfiles similares a los de la Laguna de Bustillos. Centros educativos que fueron cerrados entre 1997 y 2000 y cuyas matrículas también fueron concentradas en centros CREI. Fue así como el trabajo realizado en la zona de la Laguna de Bustillos se completó con entrevistas realizadas en la comunidad de Rancho de Peña, en el entronque a Parral de la autopista Chihuahua-Cuauhtémoc y en otras tres comunidades del municipio de Guerrero.

Se sometieron los productos de estos acercamientos cualitativos a la realidad estudiada a un análisis basado en la teoría fundamentada de Glaser y Strauss, conocida también como Grounded Theory (Glaser y Strauss, 1967), a partir de la cual se hace posible construir un aparato explicativo desde los datos recopilados en el campo. Para ello se utilizó un arreglo matricial en la búsqueda 
de categorías analíticas integradoras del modelo explicativo. El propósito general del análisis consistió en buscar los sentidos profundos de los que estaban dotadas las escuelas rurales mientras estuvieron en funcionamiento para todos aquellos que estuvieron con ellas.

La aplicación de la teoría fundamentada en el análisis de los fenómenos socioculturales, y de manera más específica, de las realidades escolares del pasado, es sumamente potente, porque hace posible la construcción de modelos explicativos de alta complejidad para comprender los eventos que se estudian y el papel de los sujetos e instituciones en ellos. Este mirador teórico-metodológico se complementa de manera natural con la visión microhistórica del pasado, dado su interés por revisar la vida cotidiana y los procesos micropolíticos y simbólicos que operan en ella. Se trata de una mirada de anticuario a los eventos que abordamos, pero con la potencia de la teoría fundamentada.

Con estos insumos se construyó, a partir de un arreglo interpretativo matricial, una narrativa basada en los recuerdos de las y los informantes acerca de su vida en la escuela rural, en cómo estos espacios eran sumamente importantes para la vida de las familias y de las propias comunidades, en los procesos de observación que conducimos y en la evidencia física recopilada durante nuestras visitas de campo a las escuelas rurales cerradas. En todos los casos pudimos ser testigos de un sentimiento de añoranza de las escuelas en operación, que dotaban de vida a cada comunidad. Si tuviéramos que resumir el resultado de este proyecto de investigación en una sola palabra, esta sería sin duda añoranza. Las y los informantes en todos los casos expresaron recuerdos, anécdotas, remembranzas, de los días de operación de las escuelas. Este sentimiento compartido de añoranza es en muchos casos acompañado de una posición crítica con respecto a la decisión del cierre de los espacios educativos. 


\section{LOS DÍAS DE GLORIA}

La experiencia social de la escuela es posiblemente el elemento más valioso e interesante de los servicios públicos, juntos con sus servicios de salud. De la escuela pública se decanta la escuela rural, elemento clave en las políticas públicas mexicanas del siglo pasado: de la escuela rural emerge el México de la posrevolución, el México de la guerra y la posguerra, y sus consecuencias socioculturales. La escuela rural es en muchos sentidos la madre del México de este nuevo milenio.

Las comunidades a las que la escuela pública llegó se transformaron de manera permanente. La escuela trajo consigo elementos culturales que se iban a integrar de forma profunda en las costumbres y usos de numerosas comunidades por todo el país. Fue así cómo las cadencias anuales de las regiones rurales, por ejemplo, se volvieron simbióticas con el calendario escolar; las fiestas propias de la escuela se integraron a las celebraciones tradicionales, religiosas o no, de cada ranchería. Allá en cada recodo en el que había una escuela empezaron a utilizarse términos como "asociación de padres de familia”, "graduación”, “certificado de primaria”...

Ilustración 1. Placa de fundación de la escuela. Baldón

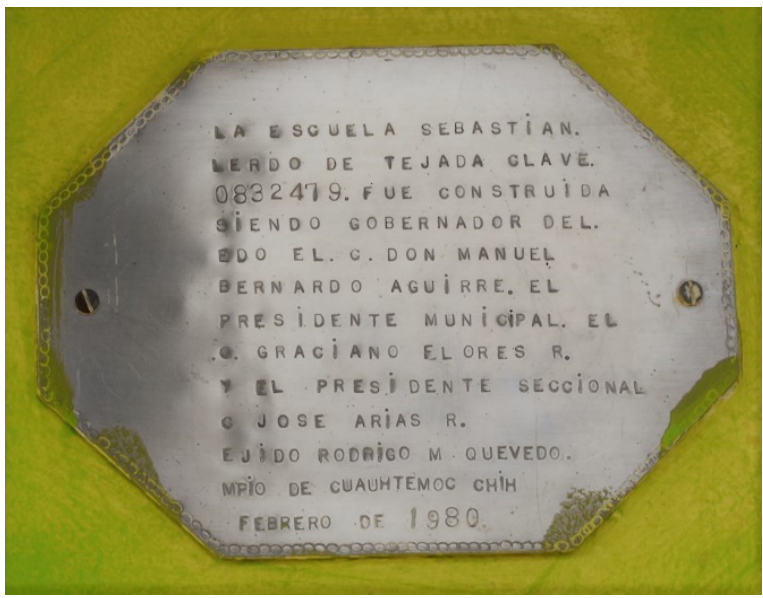


En otro sentido, la presencia de la institución educativa en una comunidad estaba cargada de significaciones culturales complejas: el rancho ya no era más un triste puñado de casitas, ya era un rancho con escuela. Esta característica orientaba procesos económicos y estratégicos para las diversas regiones. La escuela encontró su lugar en el complicado armazón simbólico que significa la cultura rural mexicana.

Como ha sido siempre, desde entonces el elemento central de la escuela era el docente. El maestro era la figura que dotaba de sentido muchos de los elementos que conformaban el manto simbólico escolar. Era el personaje que organizaba festivales y fiestas el 20 de noviembre, el que reconvenía a los chicos malcriados, quien los enseñaba a leer y a contar. Su presencia era estratégica para muchas comunidades, dado el activismo social que acompañó al trabajo docente de muchas y muchos profesores rurales desde la década de los veinte, y sin interrupción hasta que finalizó el siglo pasado. El maestro era uno de los actores estratégicos del mundo rural, de sus procesos, de sus tensiones. Era una persona que "había estudiado", y que por lo tanto tenía voz autorizada y calificación para opinar en ciertas dimensiones de la vida pública y privada de la gente en los ranchos. En un sentido más agregado, el maestro rural corporeizaba la presencia del Estado mexicano en ese mundo rural. Era la figura más visible del Estado, la más cercana, era un rostro visible en el abigarrado e imponente concepto de la autoridad.

Esta conexión con las autoridades de diversos niveles era un elemento más a considerar con respecto al profesor rural: él tenía acceso al Inspector escolar, que se situaba aún más arriba en el escalafón oficial, lo que significaba una vía institucionalizada de segundo nivel, para relacionarse con el Estado mexicano.

En no pocas comunidades el maestro rural se integraba a las mesas de autoridades en las asambleas del ejido, para discutir y aconsejar en temas de tierras, permisos, aguas, herencias. Su autoridad académica era reconocida, y su voz escuchada en estos espacios. Es importante precisar que estos procesos culturales estuvieron permanentemente acompañados de complejos procesos 
cotidianos, puesto que la acción del maestro siempre se sitúa en el ámbito de lo interrelacional. La actividad de los maestros era una actividad cotidiana, que seguía el pulso de los acontecimientos de la vida diaria de cada comunidad rural, y en esa medida tenía que ver con los ritmos agrícolas, el pulso estacional del clima, las épocas de lluvia, la época de cosecha, entre otros muchos elementos que conformaban el calendario híbrido de la escuela y de la comunidad en la que se integraba.

\section{Ilustración 2. Salón de clases. Baldón}

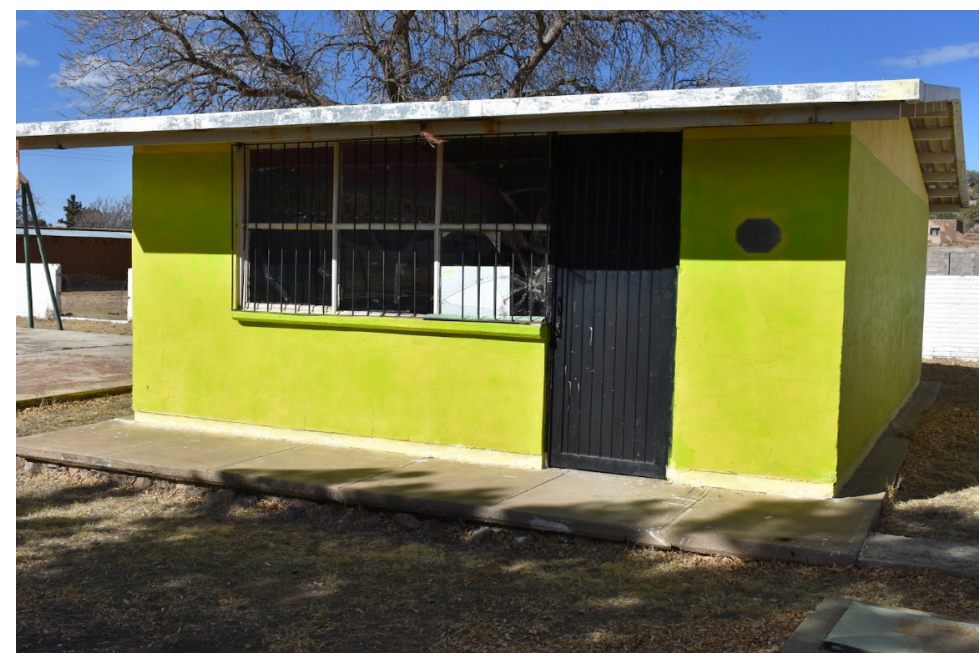

La escuela rural se percibía como la apuesta para la movilidad social de los hijos de cada familia. Era el elemento transformador por excelencia en la cosmovisión rural, en tanto instancia formadora de las nuevas generaciones. Quién sabe hasta dónde podría llegar un niño o una niña que hubiera iniciado su vida formativa en las aulas elementales y remotas de la escuela del rancho. Es así como esta institución engendraba esperanzas de una mejor vida en los puntos de vista de las familias campesinas en los ranchos de Chihuahua. Su papel transformador en muchos sentidos se convirtió en vaticinio, permitiendo que sus egresados y egresadas continuaran sus procesos de formación en escuelas secundarias 
de comunidades más grandes y, en algunos pocos casos, que chicos y chicas egresados de la escuela rural alcanzaran títulos de licenciatura. En una dimensión mucho más acotada, los niños y las niñas se transformaban de diferentes formas al asistir a la escuela rural. De pronto eran capaces de leer textos sencillos, de escribir recados, de declamar una poesía, o contaban luego de la cena en la mesa familiar algún relato sencillo leído en el libro de "Español Lecturas" en la escuela, o repetían alguna anécdota, un dato interesante provisto por el maestro. Todos estos elementos convivían de manera simbiótica con la cultura rural, la impregnaban y la transformaban en diversos sentidos.

El periodo histórico en el que estos fenómenos acontecían inició inmediatamente después de la fundación de las primeras escuelas rurales en Chihuahua, hacia el final de la década de los veinte del siglo pasado, y de manera muy especial luego de la puesta en marcha del llamado Plan Chihuahua, en la administración del gobernador Teófilo Borunda Ortiz (Guzmán y Orozco, 2012). Se trataba de una época en la que ninguna instancia de cualquier nivel de gobierno tenía un alcance tan extenso y tan profundo como la escuela rural.

Dado que otros órganos de los gobiernos federal y estatal no tenían la capacidad logística suficiente para alcanzar las comunidades rurales más alejadas en estados tan dilatados como Chihuahua, la escuela rural era el vehículo mediante el cual se transmitían informes, se repartían avisos y se promovían programas. Es esa la explicación del por qué esta institución fue la vía para la llegada de numerosos programas públicos hasta las comunidades, muchos de ellos no relacionados con asuntos exclusivamente educativos. El papel de la escuela rural en el último medio siglo es determinante para comprender una serie de procesos en el campo de Chihuahua, que trascienden las dimensiones exclusivas de los procesos relacionados con la oferta del servicio educativo. 


\section{Ilustración 3. Salón de clases. Baldón}

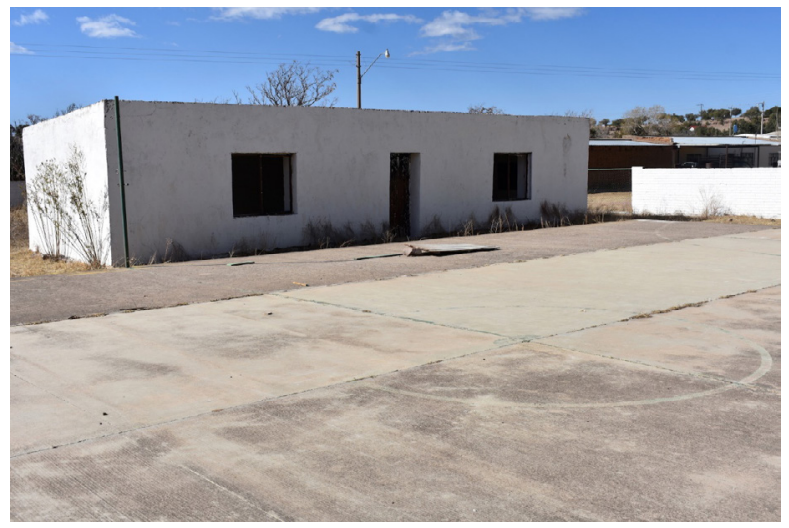

La importancia de la escuela se desdoblaba además en el proceso de certificación de estudios que tenía lugar una vez concluidos los seis años reglamentarios del nivel. En muchos casos la legitimación documental que alcanzaban los chicos mediante la obtención del certificado de primaria no tenía usos credencialistas más allá de su poder simbólico, dado que la mayoría de ellos no continuaban sus estudios de secundaria. Sin embargo, la obtención del certificado tenía potencias simbólicas muy importantes para el chico recién egresado de la primaria y para su familia. Con frecuencia el certificado se enmarcaba y se le reservaba un lugar especial en la sala, entre los retratos de los abuelos o de otros parientes. Más allá de asunciones culturales ingenuas, estas prácticas nos permiten tasar en toda su dimensión la importancia de la escuela para las comunidades rurales como un fenómeno multidimensional, complejo y de gran importancia para la vida de estos asentamientos.

Además de su importancia para la cultura y la vida rurales, en lo físico las escuelas rurales eran clave: sus explanadas se utilizaban frecuentemente para diversos actos de naturaleza muy diversa, en esos espacios se celebraban las ceremonias cívicas propias del calendario escolar, pero además eran el espacio para la celebración de comidas, rifas, kermeses, subastas, bailes de quinceañera, de bodas, entre muchos otros. La escuela en tanto es- 
pacio físico era un referente en la comunidad rural, en una época en la que sus aulas se utilizaban para la celebración de reuniones ejidales, de asesorías y talleres de numerosas instancias públicas y privadas, fiestas familiares, entre otros eventos.

En la escuela rural chihuahuense del siglo XX encontramos la instancia pública más importante en términos de su potencial para llegar hasta los espacios más lejanos y con mayor marginalidad en la entidad. En un periodo en el que la red carretera era apenas un sueño, y los servicios de internet y de telefonía celular ni siquiera se habían concebido, la escuela rural cubría una necesidad de información y de formación estratégicas para los propósitos de gobierno y educativos de la época (Vera-Bachmann y Salvo, 2016).

Ilustración 4. Interior de un aula. Baldón

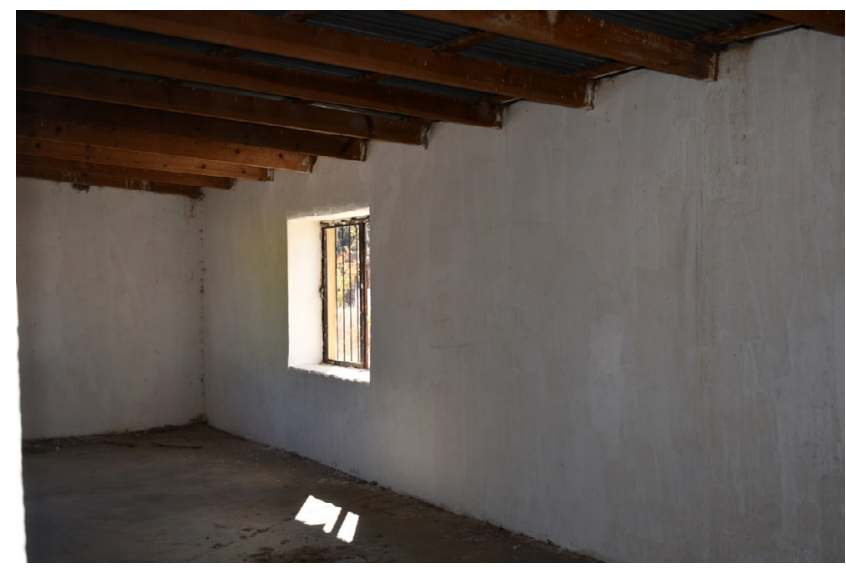

\section{LOS ESPACIOS ESCOLARES}

Las características de estas escuelas rurales son diversas y responden al momento en el que fueron construidas y a las condiciones de cada una de las comunidades que las albergaron. Es así que encontramos escuelas que contaron con energía eléctrica en algún momento de su historia, o que tuvieron la posibilidad de conectarse a la red de agua potable de la propia comunidad. Sin embargo, en otros casos la escuela estaba tan limitada como su 
propia ranchería. Había escuelas que no contaban con agua potable en la época de frío debido a que las tuberías se congelaban entre noviembre y febrero, y otras más enfrentaban en la época de Semana Santa a la amenaza permanente de que los techos de lámina se levantaran por los aires. En otras más no se contaba con cerco perimetral, por lo que no era extraño que de vez en cuando alguna vaca asomara la nariz curiosa a las actividades escolares, o que un perro osado se aventurara entre las bancas de los alumnos en plena clase.

Estas características heterogéneas de la infraestructura y del menaje con la que contaban estos centros educativos constituyó un elemento central en la construcción de la cultura escolar y de la experiencia educativa de los miles de niños y niñas que pasaron por sus aulas antes de su cierre definitivo en el ciclo escolar 96-97; constituyen buena parte de los imaginarios que estos chicos, sus maestros y las familias de las comunidades construyeron alrededor de la escuela rural.

\section{Ilustración 6. Mobiliario escolar. La Selva}

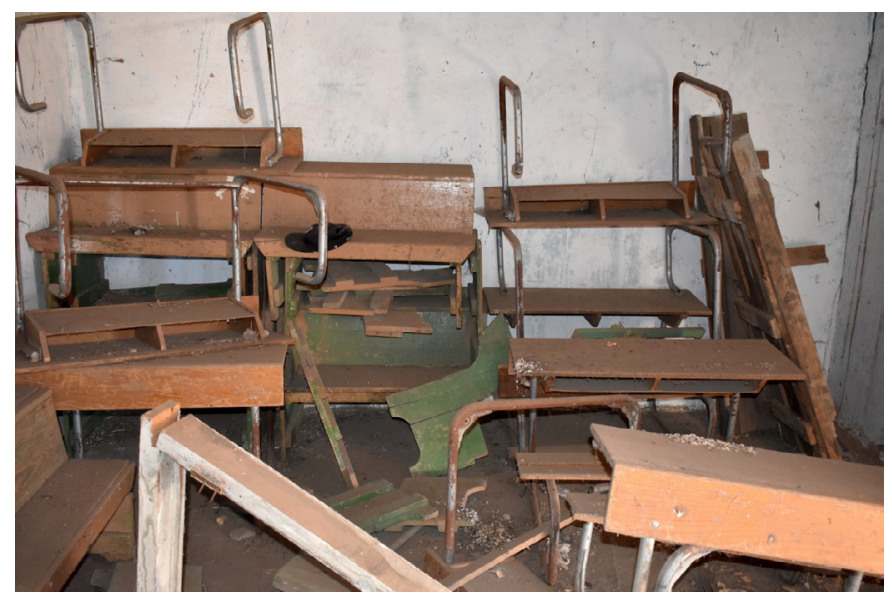

La construcción típica de las escuelas del Plan Chihuahua no distaba mucho de los estilos arquitectónicos de las casas de las comunidades: gruesas paredes de adobe con remates de madera 
en las ventanas y en las puertas, techados de cintas de madera de pino asentadas sobre polines redondos, y una capa de terrado como impermeabilizante. Normalmente a estas escuelas antiguas se les dotó con los años de rejas de metal con el propósito de impedir el saqueo y el vandalismo, aunque tampoco era raro que la escuela se mantuviera abierta, o que el acceso a sus instalaciones fuera sencillo. Durante las vacaciones y luego del cierre, en la mayor parte de las comunidades la llave de las aulas o del acceso principal al predio escolar fue entregada a la autoridad ejidal, o bien, a algún vecino o vecina que de manera voluntaria accedió a permanecer al pendiente de la escuela. En muchos casos hasta la fecha esta costumbre se mantiene.

\section{Ilustración 7. Machimbre en salón de clases. La Selva}

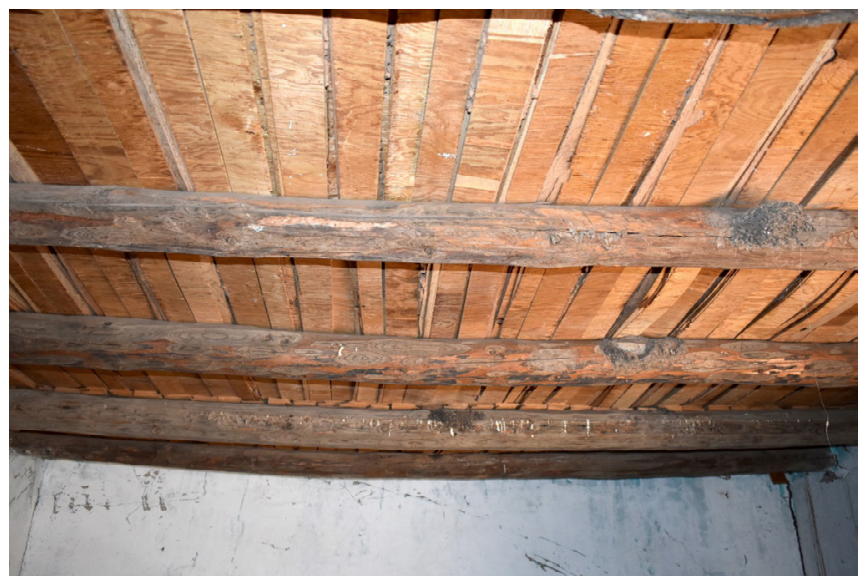

En muchas escuelas rurales el edificio original era una ristra de salones de adobe, construidos con la misma lógica con la que se erigían las casas de la época; un aula era seguida por otra, en un chorizo elemental a un lado del cual se tendía una plancha de cemento sin las medidas reglamentarias de ninguna cancha deportiva. Estaba presente en la concepción arquitectónica de estas escuelas remotas la idea del centro escolar, y se ejecutaban con más buena fe que con pericia técnica. Aunque los primeros protocolos para concebir, diseñar y construir una escuela habían 
llegado a Chihuahua desde finales del siglo XIX, en muchas comunidades rurales estos eran ignorados, así que la escuela se construía con los recursos y las ideas que estaban a la mano. En algunos casos el centro educativo se levantó en el lugar en donde se ubicaba la parcela escolar, de manera que en no pocas comunidades la escuela se asentaba lejos de las zonas dedicadas al desarrollo habitacional, entre las otras parcelas, en medio de los maizales.

Ilustración 5. Pizarrón pintado en el muro. Baldón

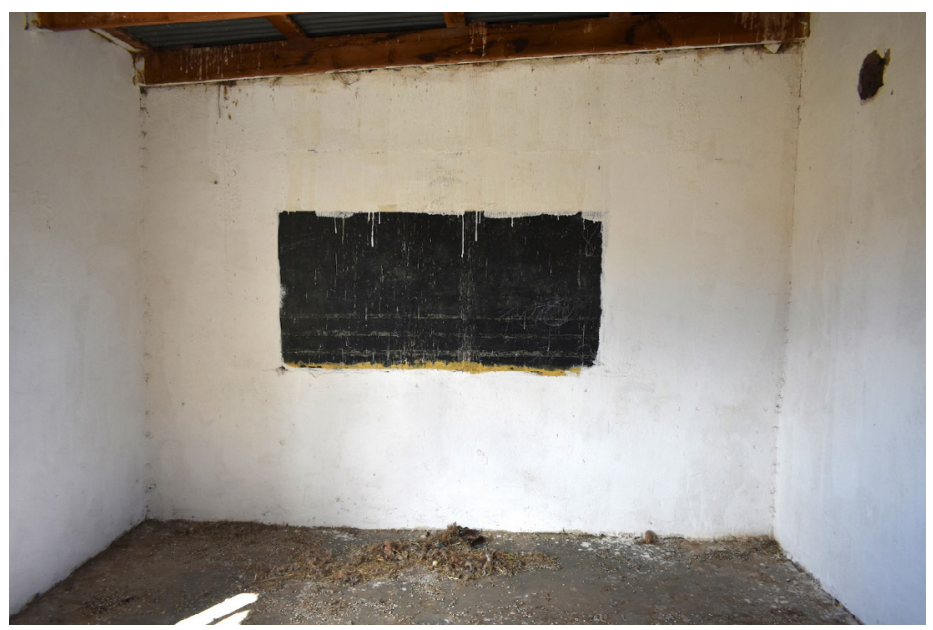

Las paredes de adobe se remataban con techados bajos de machimbre, y con un armazón de polines de madera sobre el cual se hacía descansar un arreglo de láminas metálicas. En no pocos casos esta suerte de sombrero fue levantada por los ventarrones de febrero y marzo, incluso en momentos en los que las aulas estaban ocupadas por los niños y sus maestros. Hasta la fecha muchos de esos techados se aferran con sus uñas de madera a los muros de adobe.

En la mayor parte de los casos, los ventanales y puertas de las escuelas eran de madera, cubiertas con pinturas de aceite. Se trataba de los mismos remates arquitectónicos existentes en cada casa de las comunidades perdidas entre los meandros de la 
sierra o en los llanales chihuahuenses. Ventanas pequeñitas, para combatir el frío, que significaban espacios cerrados oscuros, pero calientitos. Las puertas se aseguraban con aldabas ingenuas de metal, o con candados chirriantes, que normalmente cedían al primer golpe de una piedra, o se desarmaban herrumbrosos por el rocío o por las lluvias.

El espacio de las aulas rurales se completaba con pisos de terrado, y luego con el tiempo de cemento, o de "firme" en la mayor parte de las comunidades. En otras, las menos, los pisos eran de listas de madera de pino, irregulares, hambrientas de devorar cada lápiz o borrador que caía entre sus rendijas. Con el tiempo algunos de estos pisos se han levantado, y revelado colecciones de útiles escolares intemporales: lápices mordisqueados, sacapuntas sin navaja, resistoles de boliche sin su sombrero bombín.

Ilustración 8. Casa del maestro. Baldón

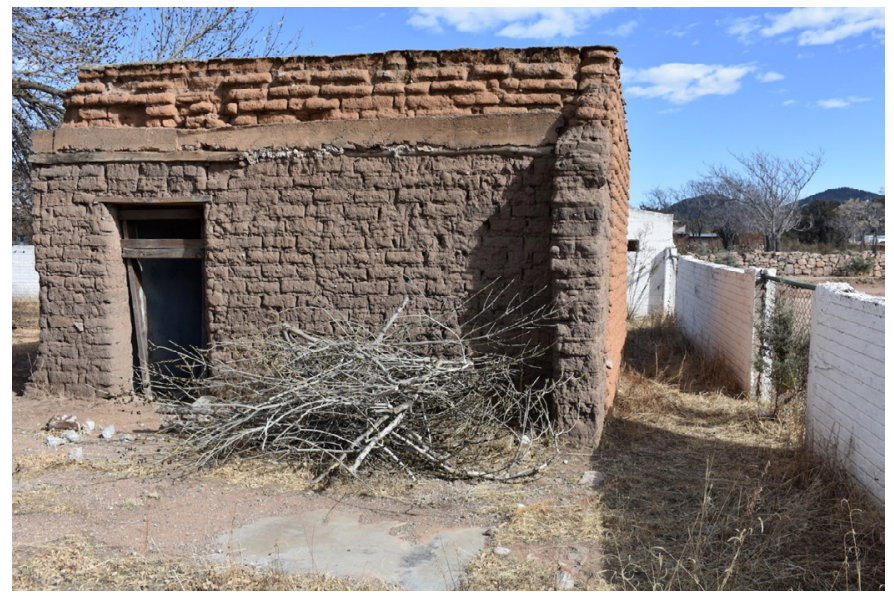

A las aulas y a la plaza cívica normalmente se les añadía la casa del maestro, que en todos los casos no era más que un cuarto situado en uno de los ángulos del solar de la escuela. Ahí pasaba las tardes y las noches el maestro o maestra de la escuela, en esas habitaciones solitarias que servían de dormitorio, cocina y estudio. Los baños siempre se situaban lejos, no adicionados al cuerpo 
de la casa del maestro, sobre una fosa séptica. Así que para ir al baño el maestro debía armarse de valor y recorrer el frío entre su alojamiento y las casetas de los baños. Esto ocurría por las noches en la oscuridad, porque las casas del maestro rara vez contaban con servicios adicionales como luz eléctrica o agua corriente. Eran estos espacios sumamente modestos, congruentes con la visión que desde la política educativa de la época se impulsaba acerca de la educación pública, y con los procesos identitarios gremiales de los profesores de ese momento histórico en México.

En estas escuelas rurales existían espacios especialmente cargados de simbolismo. Uno de ellos era el pórtico, por donde los chicos ingresaban cada día al patio y luego a las aulas; la campana escolar, que en algunas pocas comunidades era de bronce, llegadas a los ranchos mediante la aplicación de un programa oficial que en los años setenta dotó de estos objetos a muchas escuelas en Chihuahua; antes de ello en la mayoría de los planteles era un riel del ferrocarril sostenido en vilo por un alambre que era golpeado con algún objeto de metal para anunciar los ritmos de la escuela. Allá se escuchaba en el fondo de los valles el eco metálico del riel, anunciando el recreo, el inicio o el fin de la jornada escolar.

Un elemento importante más era el pizarrón de anuncios. Normalmente se trataba de un pizarrón en desuso, que se destinaba a fijar información diversa en hojas o carteles enviados por alguna instancia de gobierno o particular. Ahí se pegaban con cinta adhesiva los anuncios de las campañas de vacunación, o se anunciaban las próximas fiestas patronales, o la lista de la tanda, o los padres de familia que debían la cuota escolar. En comunidades como las que alojaban a estas instituciones educativas, la escuelas y las tiendas de abarrotes, los comercios, eran espacios estratégicos para la difusión de la información. 


\section{Ilustración 9. Casa del maestro. Baldón}

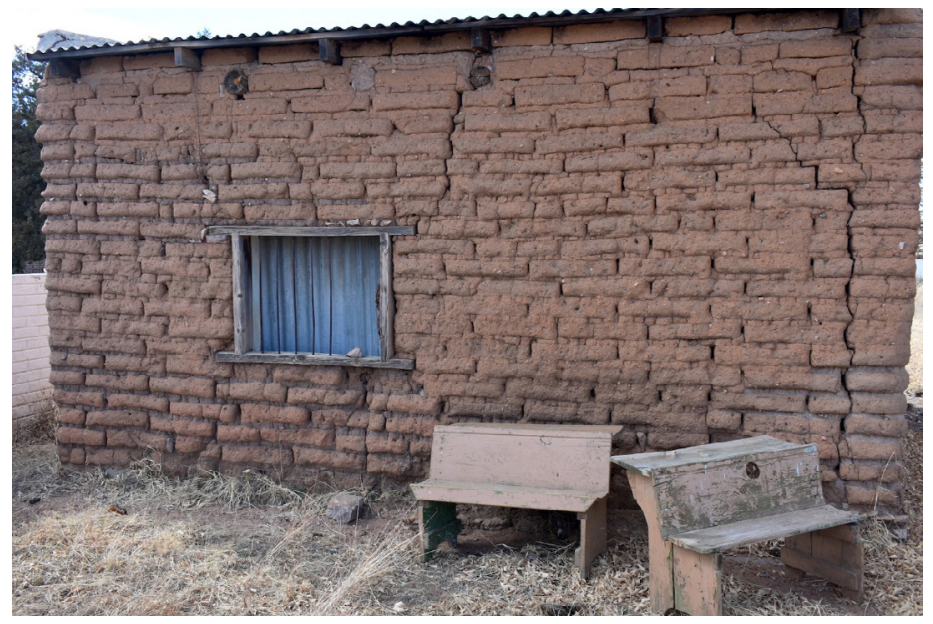

Algunas escuelas rurales contaban además con cancha escolar, equipada con una o dos canastas de basquetbol. Ocasionalmente se contaba con balones para este deporte, o para el futbol, que con frecuencia se practicaba en el mero llano, con porterías de piedras o chamarras hechas bola. En algunas comunidades se practicaba además en la cancha de las escuelas el voleibol, o el rebote en alguna pared. Estas prácticas alcanzaron en muchos ranchos a los adultos de la comunidad, que se integraban a los torneos y a las retas por las tardes, en las épocas de tranquilidad en las labores del campo.

Las escuelas compartían una característica arquitectónica sin excepción: en todas ellas se levantó en algún momento de su historia una astabandera, dotada de un sencillo mecanismo de poleas para levantar por los cielos al lábaro patrio. Era este un rasgo inequívoco de la escuela rural en Chihuahua: en esas agujas ondeaban el 24 de febrero y el 16 de septiembre las banderitas sencillas, guardadas en algún gabinete en las aulas (casi en ninguna parte se acondicionaba un espacio como dirección). Hoy en todas las escuelas que visitamos persisten las astabanderas tercas, verticales, con sus mecanismos oxidados y las líneas de acero reventadas por la contundencia combinada del tiempo y la intemperie. 
Algunas escuelas rurales contaban con una adición arquitectónica importante: una troje de adobe para resguardar el grano cosechado de la parcela escolar. Estos espacios eran generalmente galerones erigidos dentro del predio de la escuela y se aprovechaban de manera estacional para el acopio del maíz o frijol cosechado de la milpa por los padres de familia,; las ganancias obtenidas se destinaban para sus gastos especiales, para financiar alguna construcción adicional o para su mantenimiento. El tema de las parcelas escolares en Chihuahua es un asunto que se ha estudiado poco y que resulta muy interesante dados los usos variados que estas dimensiones de la escuela recibían. Mientras el maíz crecía cada junio en dilatadas ristras en la parcela escolar, la troje se llenaba de grano y en casi todos los casos de ardillones y otros roedores, lo que hacía indispensable la presencia de una familia de gatos en la escuela.

Ilustración 10. Panorámica de la escuela primaria. Tres Lagunas

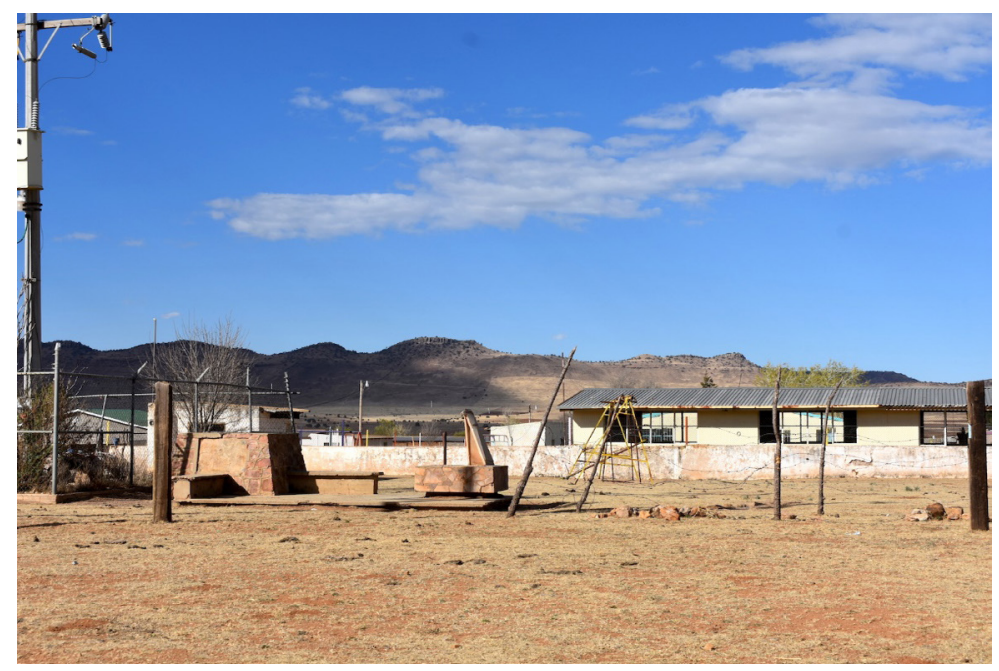

Cuando pasaba la época del grano, las trojes se utilizaban como salones de actos, para la celebración de festividades y asambleas en la estación de frío. En algunos casos estas galeras se acondicionaban con rudas bancas de tablones para el acomodo 
de los invitados de la boda, o de los ejidatarios los domingos de asamblea. En otros casos, estos eventos se celebraban con la gente de pie y en la troje sonaba en las cuerdas del violín, la guitarra y el tololoche El corrido del año nuevo y con las voces desgraciadas del trío del rancho: desafinados, borrachos, incansables.

El epicentro del universo en la escuela rural era el aula. Era en ese espacio en el que se desarrollaba el trabajo cotidiano de los docentes en condiciones fuertemente asociadas al contexto. La mayoría de las escuelas contaba con piso de concreto, pulido a mano, y con poco más equipo que un pizarrón de color verde. En algunas aulas el pizarrón era una ilusión pintada directamente encima de uno de los muros, en el que los maestros escribían utilizando gises blancos o de cal. El menaje principal de las aulas, los mesabancos, se completaba en una colección disímbola de estilos, reflejo de la evolución histórica de estos muebles. Algunos eran binarios, con la forma de una zeta, de madera burda, y ocasionalmente barnizados, diseñados para que la parte trasera del pupitre sirviera como mesa del estudiante de atrás. Estos son los mesabancos más antiguos de estas escuelas de rancho. Luego estaban los pupitres basados en marcos de metal, de los ochenta y principios de los noventa, provistos con asientos de plástico azul o naranja, y con los logotipos de las administraciones estatales que los produjeron. En algunos pocos casos el equipo para los estudiantes se completaba con pupitres unitarios, igualmente construidos a partir de una estructura de metal, con paleta de madera y respaldo de plástico. En todas las escuelas que visitamos, los pupitres de diferentes generaciones convivían en las aulas, en filas irregulares, mostrando la evidencia de la presencia de los niños: en la mayoría de las mesas de los pupitres se conservan innumerables testimonios de alumnas y alumnas en la forma de tallas, dibujos, frases cortas, nombres, y cuentas sencillas.

En el extremo del aula se mantenía otro elemento central de la vida escolar, cargado de profunda significación: el escritorio del maestro. Era este el espacio simbólico de la autoridad cotidiana, a donde había que ir a revisar, y en donde normalmente se situaban las pertenencias sencillas del profesor rural: el cuaderno, la planea- 
ción, la pluma. Los escritorios que encontramos constituyen, como los pupitres, un recorrido por la historia de la escuela rural chihuahuense: escritorios de madera burda, elaborados por la mano del carpintero de la ranchería, escritorios de metal, enviados desde la SEP, en México. Este mueble con carga simbólica fue tomando el rostro de los tiempos en los que llegó a la escuela del rancho.

En muchas de aquellas aulas, hoy abandonadas, se conservan las huellas del uso de calentones de leña para combatir las inclemencias invernales. La práctica de que los niños llevaran a la escuela durante el invierno un leño para el calentón era común. De esa manera las familias contribuían a conservar el calor en el aula. Hoy en día algunos muros conservan la herida circular por la que escapaba el tubo del calentón. En otros casos, huellas de ceniza antigua, o virutas esparcidas por el piso, marcan el lugar que alguna vez fue el más calientito del salón.

\section{LAS FECHAS IMPORTANTES}

El inicio de clases marcaba en las comunidades rurales el final de periodos vacacionales que eran mucho más dilatados de lo que son ahora. Las vacaciones de verano duraban en aquél entonces más de dos meses, durante los cuales los niños y niñas normalmente se olvidaban por completo de la actividad escolar. Las escuelas rurales no tenían uso durante aquellas semanas de calor y lluvia, por lo que lo normal era que en los primeros días de septiembre, cuando reabrían sus puertas, sus patios estuvieran cubiertas de hierba. En muchas comunidades, en los primeros días de septiembre se organizaban jornadas voluntarias entre los padres de familia para reacondicionar estos espacios.

Arrancaba el ciclo escolar e iniciaba el recorrido cíclico por sus fechas. La primera del año era el 16 de septiembre, que en todos los pueblos con escuela era una fecha importante, en la que el centro educativo se adornaba con motivos tricolores de papel de china. En algunas comunidades los docentes organizaban pequeños desfiles conmemorativos, y en algunos casos, la autoridad del rancho daba el Grito. Era esta fecha la primera del ciclo escolar en 
la que se utilizaba el espacio de la escuela como un centro comunitario, público, que congregaba a las familias para presenciar el bailable o la ronda infantil preparada por los niños y los maestros para tal fin.

\section{Ilustración 11. Escuela primaria. Tres Lagunas}

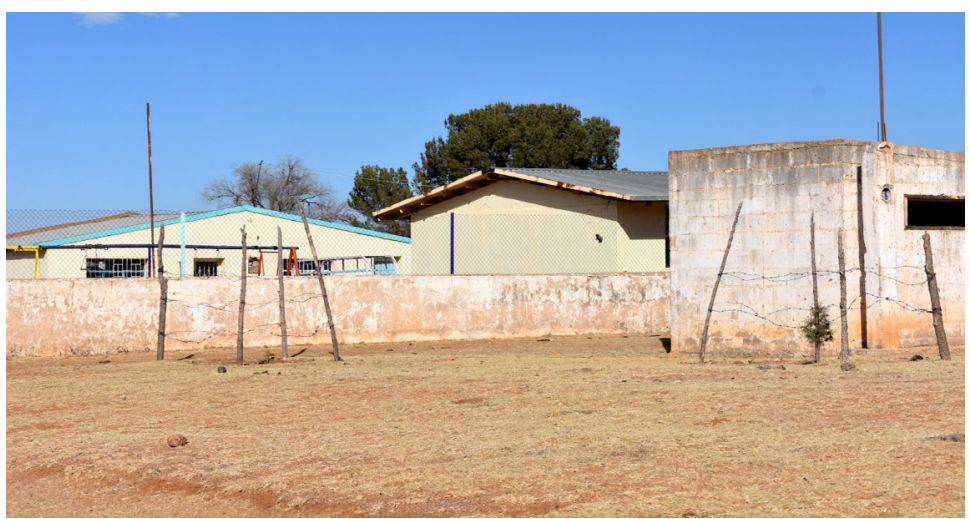

Seguía en el calendario escolar el 20 de noviembre, que para muchas de estas comunidades era la celebración más importante del año, y se aprovechaba para realizar la fiesta anual. Coincidía la celebración para conmemorar el inicio de la Revolución de 1910 con el momento en el que concluían las actividades de trabajo con el maíz o frijol y la cosecha de la manzana, por lo que en varias comunidades rurales - sobre todo en aquellas que no contaban con santo patrono-, el 20 de noviembre era el momento anual para el festejo.

Los coleaderos eran un evento obligado en muchos veintes de noviembre, con ganado flaco que los vecinos aportaban para el programa del día, que consistía en montarse sobre la muestra de ejemplares vacunos que respingaban ante el peso en sus espaldas. Y de pronto allá iba por los aires Martín, el del comercio, y se secaba la sangre de la frente Armando, el presidente de la asociación de padres de familia, luego de levantarse de la arena improvisada en algún corral. Con frecuencia las fiestas escolares incluían otros juegos y entretenimientos que eran organizados y 
disfrutados por la comunidad entera: el marrano o el palo encebado, los aros (que consistía en colgar pequeños aros a alguna altura y pasar a caballo a toda velocidad para ensartarlos con una vara) o el violentísimo juego del gallo enterrado, donde se cubría al animal hasta el pescuezo para que los hombres de la comunidad pasaran a toda velocidad a caballo y lo arrancaran de su sepultura.

Las navidades eran otro momento importante en los ritmos de la escuela. Se asociaban con las fiestas tradicionales del fin de año, normalmente marcado por las fiestas religiosas y por el receso de clases de diciembre. Muchos niños y niñas conocieron el concepto de Santa Claus en sus profesores rurales, quienes se confeccionaban un traje para la foto navideña; y se volvieron tradicionales las posadas escolares, donde se compartían sencillos banquetes cocinados por las familias: tamales, atole, ponche y bolsitas con dulces, cacahuates y mandarinas. Estas mismas bolsitas se repartían también durante el Día del Niño, en abril. Esta celebración fue un elemento más que las escuelas rurales trajeron a la cultura del rancho. Los maestros, con la colaboración de algunos padres de familia, organizaban la fiesta para los niños, que incluía romper una piñata, juegos y comida sencilla.

El Día de las Madres era un evento especial que concentraba a las mamás en el patio de la escuela; era una de las pocas ocasiones que por aquellos años tenían las mujeres de estas comunidades rurales para lucir el vestido enviado por la prima o la tía desde el otro lado, y los tacones comprados en Cuauhtémoc, o en Chihuahua. La escuela se convertía entonces en un desfile de modas en donde las bancas se acomodaban en filas sobre el patio escolar, y se servía chile colorado y arroz, como en una boda o en una quinceañera. La fiesta era amenizada con los propios niños y niñas de la escuela, que declamaban, cantaban o presentaban números de danza. La otra fiesta importante de ese mes era el Día del Maestro. El trabajo de los docentes era reconocido sin excepción por las comunidades cada 15 de mayo, fecha en la que muchas familias les enviaban regalos sencillos o los invitaban a comer a la casa. 
Todas estas fechas se integraron a la manera en la que las comunidades vivían la vida. Se trata de un fenómeno de transculturación, y de la emergencia de nuevas formas de construir los significados en el contexto de la comunidad rural chihuahuense (Gregòri, 2008). Emerge así la institución escolar como elemento aglutinador de la cultura comunitaria a través de sus ciclos, que se integraron de manera orgánica a los usos y costumbres inherentes a la vida en el rancho. Los momentos clave del ciclo escolar se completaron con la propia vida de las comunidades, complementándola y enriqueciéndola.

El trabajo en la escuela, a lo largo del año, se coronaba con la ceremonia de graduación, que en las comunidades rurales era el único evento de egresión de un nivel educativo que la mayoría de los chicos y chicas experimentarían en su vida. Se trataba de graduaciones larguísimas, con números musicales y líricos. En la graduación se apersonaban las madres de familia en sus mejores galas, y el papá del graduando con su sombrero bueno. Estaba extendida la costumbre de elegir un padrino o madrina de graduación, y en muchas comunidades, al final de la ceremonia, iniciaba el baile. La ocasión además frecuentemente se celebraba matando un marranito, o incluso una vaca, para convidar la comida a toda la comunidad.

\section{LA VIDA COTIDIANA ESCOLAR}

En la mayor parte de las escuelas rurales hoy abandonadas, la jornada escolar iniciaba a las ocho de la mañana y se extendía hasta la una de la tarde. Los turnos discontinuos cayeron en desuso desde mediados de la década de los ochenta, pero en muchas comunidades la tradición de acudir a la escuela por la mañana y por la tarde se mantuvo hasta años después, dada la presencia permanente del docente en la institución. En todas las escuelas que visitamos se contaba con casa del maestro, lo que hacía posible que los profesores permanecieran toda la semana presentes en el centro escolar. Fue así que su presencia hizo posible que las escuelas recibieran otros usos adicionales a los meramente educa- 
tivos por los habitantes de las rancherías. En algunas localidades los maestros organizaban torneos de voleibol o de basquetbol por las tardes, u organizaban talleres de costura con las mujeres del rancho. Estas actividades extraescolares llevaban la cultura de la escuela y de sus profesores más allá de la actividad de clases, y situaban su práctica docente mucho más allá de los muros de la escuela. Una exalumna de la primaria de Tres Lagunas nos dijo que:

¡Ande! Aquí antes todo los organizaban los maestros en la escuela. Yo me casé ahí en el salón de actos, y el baile lo hicimos en la cancha. Se ponía muy suave. Todo era ahí en la escuela, hacíamos los coleaderos y todo, y las graduaciones, pero ahorita ya tiene años cerrada la escuela, muy triste porque muchos pasamos por ahí; por decir, mi mamá ahí estudió, y luego yo hice toda la primaria y una de mis hijas sí alcanzó a ir aquí a la escuela, pero luego ya no (Informante 2, 2018).

Una expresión especialmente interesante de la vida educativa en los ranchos la constituían las reuniones de padres de familia. De forma periódica, los docentes convocaban a estas juntas, a las que acudían solo los hombres de cada familia. Estas asambleas eran muy distintas a lo que se vive hoy en día. Los hombres de la comunidad ejercían su poder en una sociedad tradicional y eminentemente patriarcal, que se manifestaba en su presencia exclusiva en estas ocasiones. Los hombres convocados a esta reunión respondían sin falta a estas asambleas, que normalmente se aprovechaban para discutir asuntos relacionados con la propia escuela, pero también temas generales de la comunidad. La presencia eminentemente masculina en las juntas de padres de familia era un reflejo de la importancia que las familias concedían a las reuniones en la escuela, y significaban la oportunidad para ventilar temas de la mayor importancia.

Otro elemento importante de la vida cotidiana en las escuelas de los ranchos era el alimento. En la mayor parte de estas escuelas no existía una tiendita escolar, los chicos acudían a estudiar con 
bastimentos sencillos preparados por la mamá, en casa. En algunos pocos casos los docentes se organizaban para mantener un inventario sencillo de dulces, frituras y otros productos que ellos mismos vendían a los niños durante los recreos. Estos pequeños ejercicios de tiendita escolar contribuían a la pobre variedad de la alimentación de los chicos en los ranchos, que en casa mantenían dietas muy tradicionales. El alimento se conformaba de frijol, refresco, productos lácteos y de maíz, y algunos productos enlatados, especialmente la sardina.

Los niños y las niñas se alimentaban de manera sencilla, pero no dejaban de acudir a la escuela desde las casas desperdigadas por las rancherías. Las matrículas de estas escuelas de rancho nunca fueron numerosas, por lo que las instituciones que estudiamos rara vez alcanzaron la modalidad administrativa de organización completa, con seis grupos escolares funcionando al mismo tiempo. Lo más frecuente fue la presencia de dos o tres docentes que atendían a los estudiantes de los diferentes grados de la primaria en una misma aula, por turnos, mediante el sistema multigrado de organización del trabajo docente. Uno de los docentes era el director encargado del plantel, quien aparecía como responsable de la estadística educativa, o formato 911, ante la inspección escolar (Brumat, 2011). Estos docentes de rancho no contaban con apoyos adicionales para el desarrollo de las actividades educativas, de modo que eran ellos los encargados del aseo de las aulas, de las clases complementarias, como educación física y artística, y de todo lo relacionado con la escuela. Los testimonios del docente rural son muy amplios y han sido recogidos en otros textos, y constituyen un acervo simbólico y educativo de gran valor para la historia nacional en el siglo XX (Pacheco, 2013).

En el ejercicio docente emprendido en el contexto de la escuela rural chihuahuense, un elemento definitorio lo constituyeron los libros de texto gratuitos, y más adelante los acervos del Rincón de lecturas. Desde su fundación a finales de la década de los cincuenta, la Comisión Nacional de los Libros de Texto Gratuito (ConAliteG) proveyó a todas las primarias públicas mexicanas de sus acervos bibliográficos y de trabajo para el aula (Rizo, 2012). 
En la escuela rural, estos libros se cargaban de un enorme valor, mucho más allá de lo meramente educativo. Para muchos habitantes de las rancherías, los libros de la Conaliteg fueron los primeros que existieron en casa. Estos textos, impresos en papel revolución y con ilustraciones a todo color, eran el objeto que significaba la presencia de la escuela en casa. Muchas familias leían los textos sencillos contenidos en aquellos materiales, o ayudaban a la tarea por la tarde. Además de hacer más sencillo el trabajo de los docentes, estos textos constituyeron uno de los elementos simbólicos más importantes para la experiencia de la escuela rural en Chihuahua (Valencia, 2014).

\section{Ilustración 12. Casa del maestro. Tres Lagunas}

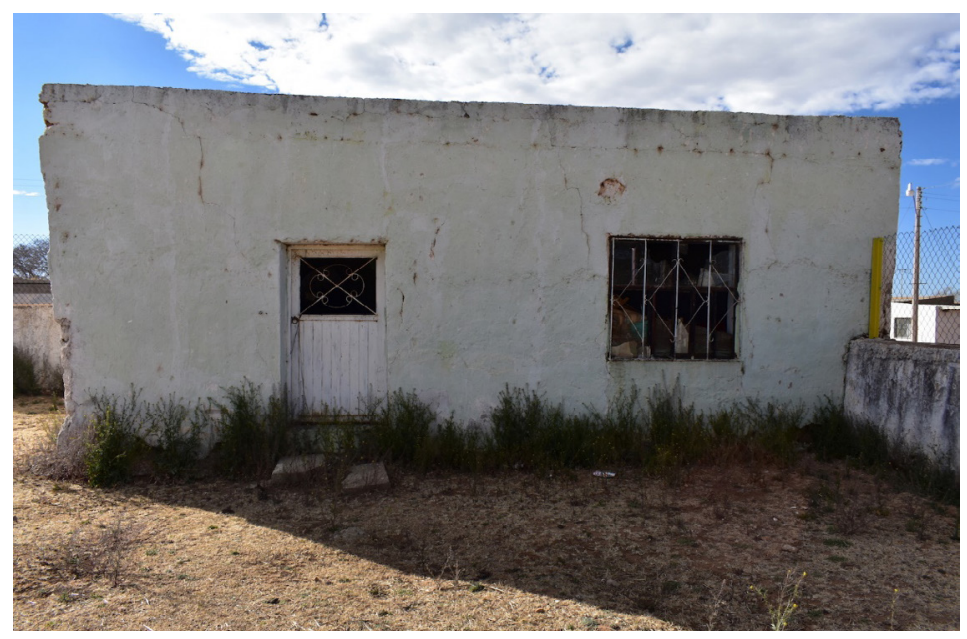

La práctica docente era otra. Muchas escuelas no contaban con luz eléctrica. No se conocían los avanzados recursos digitales que llegarían a los salones de clase años después y que marcarían la forma de aprender y de enseñar de nuestros tiempos. La conectividad que hemos visto avanzar en la década reciente era apenas un esbozo en los años en los que estas escuelas florecían. En estos asentamientos el medio de comunicación por excelencia era la radio, por medio de la cual se conocían los éxitos musicales 
más recientes, y se difundían los mensajes a manera de recados radiofónicos, para saber de una reunión en la cabecera municipal, o del deceso de un pariente, o de la llegada próxima de algún familiar (Arias y Pilar, 2016). No fue sino hasta los primeros años de la década de los noventa cuando en algunos ranchos comenzaron a instalarse rotundas antenas parabólicas, que hacían posible contar con señal para la televisión. Antes de eso, en algunas localidades se usaba ese aparato conectándolo a la batería del tractor en ritmos estrictamente controlados para conservar la batería de ese dispositivo. Algo similar ocurría con la señal del teléfono celular, que en algunas localidades solo se conseguía mediante el ascenso a alguna loma cercana, y hasta allá se iban los maestros cuando había necesidad de establecer comunicación con el mundo de fuera del rancho.

Hablar de la presencia de estos aparatos en los ranchos y en sus escuelas es adelantarnos mucho, y significa referimos a los últimos años de funcionamiento de los centros educativos que estudiamos. En realidad, durante la mayor parte de su historia, tanto las localidades rurales como sus escuelas permanecieron mayormente inconexas. Estas localidades se sitúan lejos de la ubicación de las oficinas de supervisión escolar, por lo que la presencia de las autoridades educativas en esos planteles era rara.

En estos ranchos emergieron experiencias y prácticas docentes innovadoras, que permanecen en la oscuridad. Muchos maestros y maestras desplegaron su talento en la oscuridad del aula rural, lejos del reflector de las instituciones educativas de las grandes ciudades de Chihuahua. No contamos con trabajos de rescate sistemáticos al respecto, sin embargo, no queda duda de que fueron cientos los maestros y maestras rurales que durante el siglo XX protagonizaron innumerables procesos educativos innovadores. Estas prácticas se limitaban a los recursos didácticos a la mano, en localidades en las que no se contaba con ningún recurso de apoyo didáctico, ni de medios para adquirirlos. Las papelerías y mercerías más cercanas a menudo se ubicaban a dos o tres horas de camino, por lo que los docentes debían utilizar cualquier material de trabajo disponible. En esas condiciones, los libros de 
texto gratuito de los que ya hablamos eran de gran valor. Estos recursos se complementaban con cajas de gises blancos o amarillos, y con poco más. Los docentes contaban con el valor agregado de la cercanía de la escuela rural con el medio, lo que facilitaba el abordaje de ciertos contenidos curriculares, pero para muchos otros, el desafío era doble.

Algunas pocas escuelas rurales contaban adicionalmente con un recurso valioso de esos tiempos: el mimeógrafo, que facilitaba la reproducción de materiales escritos. Estos aparatos funcionaban mediante la elaboración de un esténcil que se picaba con una máquina de escribir, y que luego servía como modelo para la impresión sobre hojas de papel revolución. Los afortunados docentes que contaban con uno de estos aparatos y el acceso a una máquina de escribir podían producir contenidos escritos con cierta facilidad. En esas pocas escuelas el aroma a tinta y a papel revolución era inconfundible, y algunos antiguos archivos escolares conservan hoy en día documentos realizados con los mimeógrafos manuales.

La inmersión de las escuelas rurales en el mundo rural hacía fácil emprender excursiones de estudio a algún arroyo, o al rancho de algún vecino. Era sencillo encontrarse con los fenómenos de la naturaleza estudiados en los libros, porque muchos eran parte de la vida cotidiana de los niños y las niñas. Casi de manera ineludible los estudiantes apoyaban a sus padres en tareas del campo, lo que les brindaba una cercanía con los procesos naturales difícil de lograr en un contexto urbano.

En esas condiciones la escuela rural chihuahuense se convertía en una institución simbiótica a la comunidad que la acogía. Se trataba de un espacio que brindaba elementos simbólicos a la vida del rancho, y que a la vez se nutría de muchos elementos culturales de su contexto. Emergía así un estilo sincrético de vivir la vida escolar, que se reflejaba en la vida cotidiana a lo largo del ciclo de estudios. 
Ilustración 13. Mobiliario escolar,. Tres Lagunas

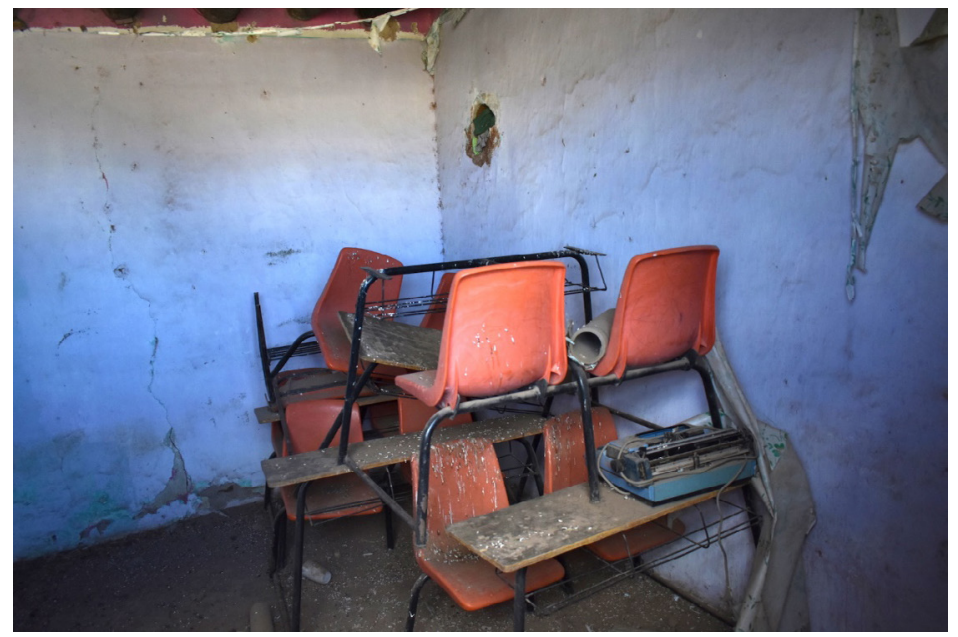

Un elemento asociado al aseo y mantenimiento de los espacios que a la fecha se ha perdido, y que tenía implicaciones muy importantes en los procesos de formación y de consolidación de valores de los chicos, era que los estudiantes se involucraban en el aseo de los salones de clase, y en el mantenimiento de los patios de la escuela. Esta actividad no era punitiva, ni se reservaba para estudiantes mal portados, sino que todos y todas se organizaban para mantener limpia la escuela, para arrancar hierbajos de sus jardines, para pintar las líneas de la cancha deportiva. Esta actividad consolidaba aún más la identidad de la institución escolar en el rancho, a través del involucramiento intenso de toda la comunidad escolar en el mantenimiento y aseo de la escuela.

\section{LA ESCUELA Y LA COMUNIDAD}

En el desarrollo sincrónico de la institución educativa del rancho, podemos encontrar numerosos elementos simbólicos y culturales en los que los usos y costumbres de la escuela se imbricaron profundamente con los de la comunidad que la acogía, en un proceso de ida y vuelta. La escuela dejó su impronta en la ranchería, pero lo mismo esta en aquella. Se trata de un proceso altamente signifi- 
cativo para la vida rural en Chihuahua, que marcó profundamente los procesos sociodemográficos de esa región durante buena parte del siglo XX.

Ilustración 14. Interior de aula. La Selva

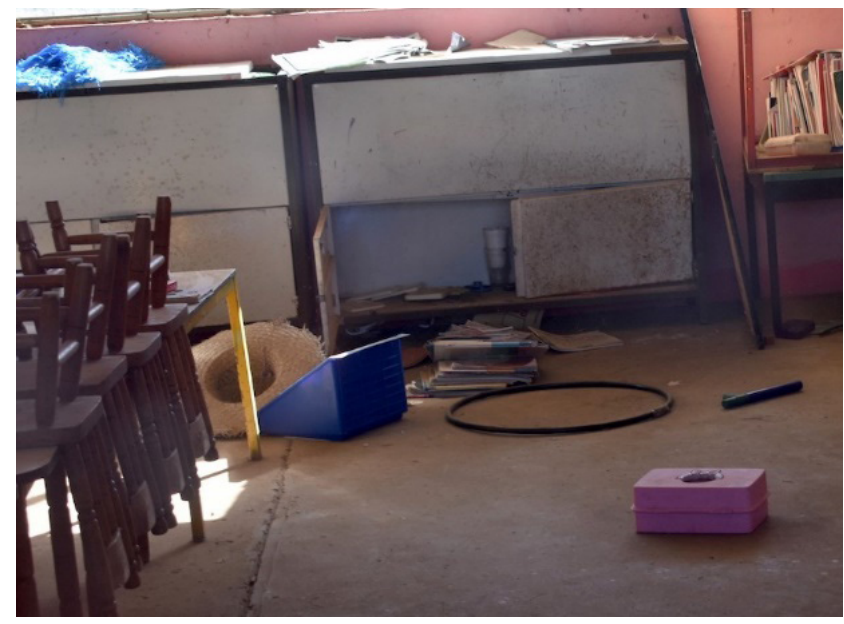

A la escuela del rancho iban casi todos los niños y las niñas, ocasionalmente alguno se ausentaba por una temporada para trabajar en las tareas del campo, o alguna estudiante perdía un año para ayudar con la atención a algún pariente anciano, pero en general la escuela significó una experiencia compartida para generaciones completas de nacidos y criados en los ranchos de Chihuahua. Más allá, luego de la graduación con música en vivo y chile colorado, fueron muy pocos los egresados que se animaron a seguir nuevos derroteros educativos, lejos de la familiaridad de la escuela ranchera. La mayoría de sus egresadas y egresados se integraron de lleno al trabajo en la labor, o en casa. El certificado de terminación de estudios de primaria se quedó colgado en algún muro de las habitaciones oscuras, de adobe, de techos bajos y ventanas con marco de madera de pino, como trofeo y constancia del paso por las aulas.

Este trofeo tuvo un rasgo particular: en la mayor parte de las localidades que estudiamos, no se reservó solamente para los ni- 
ños o para las niñas, sino que todas y todos pudieron acceder a él sin distinción de género. Esto nos habla de la escuela rural como elemento democratizador y como espacio para la emergencia de procesos de igualdad de género. Muchas rígidas visiones mantenidas por la ortodoxa cultura bucólica se rompían en el espacio liberador de la escuela primaria del rancho, en donde las niñas se sentaban entre los niños, en donde el recreo y todas las actividades eran mixtas, y en el que las distinciones fuertemente arraigadas en la cultura ranchera entre hombres y mujeres se diluían. Resulta interesante cómo algunas informantes egresadas del aula rural recuerdan con alegría el surgimiento de procesos de sororidad entre las niñas, y de interacciones horizontales entre unos y otras. Posiblemente este rasgo haya sido una de las contribuciones más importantes de la educación rural a las comunidades rancheras en la entidad.

Ilustración 15. Salón de clases. Tres Lagunas

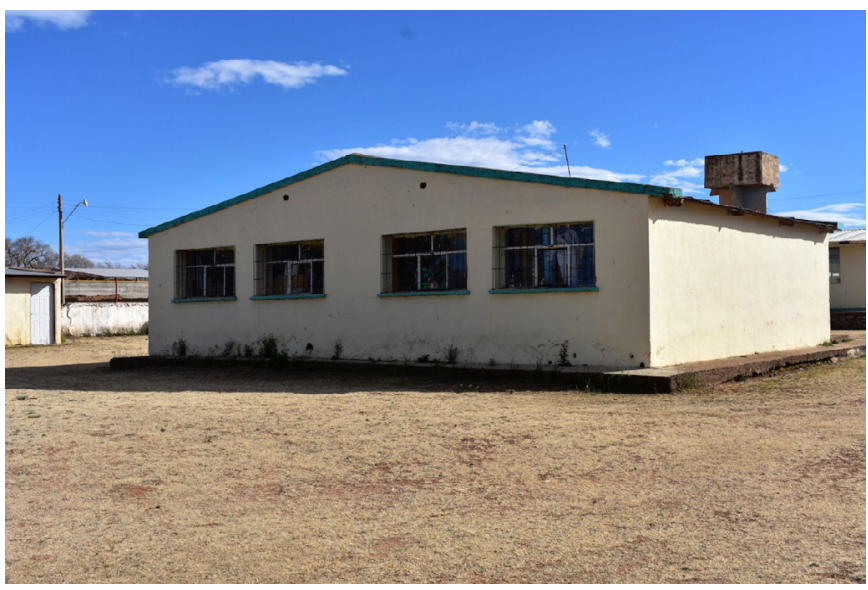

Junto con las interrelaciones personales horizontales y democratizadoras, la escuela rural llevaba a sus alumnos y alumnas los elementos básicos del currículo: la posibilidad de leer, escribir, hacer cuentas y dominar nociones de historia nacional. Las fuertes cargas simbólicas: la bandera, el himno nacional... fueron todos elementos que se conjugaban en cada jornada escolar. Varios 
elementos presentes en esta combinación cultural trascendieron el cierre de las escuelas rurales, como el béisbol, que llegó a los ranchos por medio de los docentes aficionados a este deporte. El béisbol fue un elemento que en muchas comunidades acompañó a la escuela. A pesar de que en todas estas instituciones educativas que operaron de manera intensa entre la década de los setenta y hasta mediados de los noventa existían canchas de basquetbol, el béisbol se practicaba de manera extensiva e informal, con bates hechos en casa y pelotas de trapos anudados. Las ligas regionales de béisbol que a la fecha persisten en municipios como Cuauhtémoc, Guerrero, Cusihuiriachi y San Andrés, son un producto añejo de aquellos partidos escolares celebrados en diamantes de tierra y piedras amenazantes.

Ilustración 16. Salón de clases. Tres Lagunas

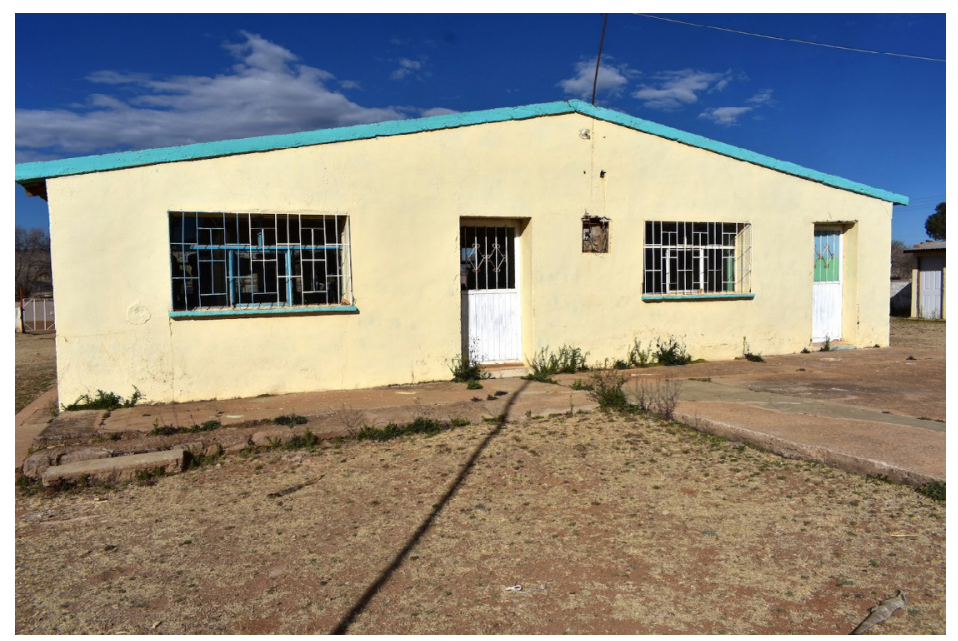

De entre los elementos culturales que la escuela rural llevaba consigo, sin duda el más poderoso era el propio docente. Las y los maestros rurales se investían de una autoridad simbólica muy importante en aquellas comunidades, por sus capacidades de gestión y por su conocimiento del mundo más allá del rancho. Se cultivaba un respeto a la figura del docente y a sus decisiones, así como a su capacidad para vigilar y castigar a los niños 
Ilustración 18. Astabandera. Tres Lagunas

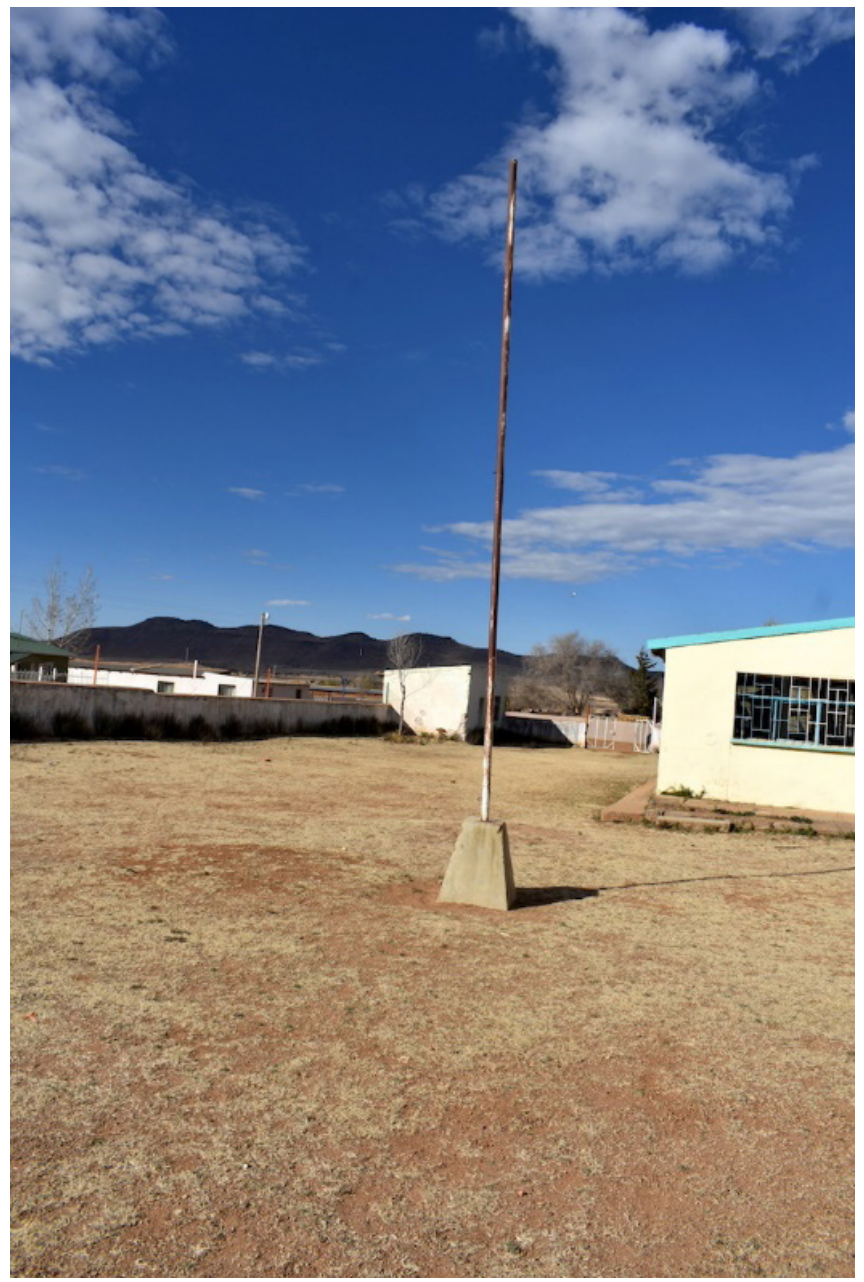

en la escuela. Este respeto se expresaba en que las familias con frecuencia enviaban alimentos sencillos al maestro: frijoles cocidos, carne de venado, huevos, piñones, y en que en la mayoría de las comunidades, los lugareños apoyaban en lo que se pudiera al maestro o a la maestra: un aventón en la troca a la cabecera municipal, una invitación a cenar... todas ellas eran muestras de esta relación entre los profesores y la comunidad en la que laboraban. 
Ilustración 17. Interior de salón de clases. Tres Lagunas

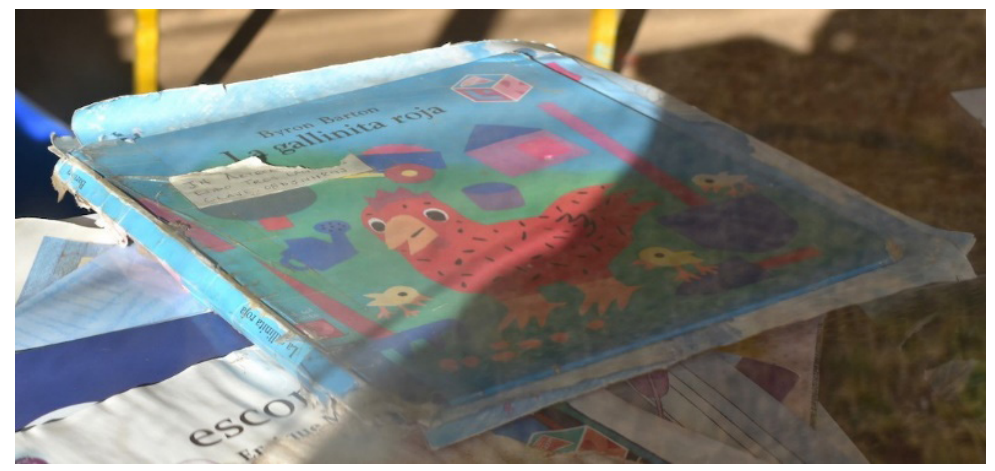

En buena medida esta experiencia de los docentes en el rancho los marcó de manera diferente a aquellos que solo ejercieron su profesión en el contexto urbano. Los docentes que tuvieron la oportunidad de trabajar en el contexto rural se aproximaron a la construcción de su identidad profesional desde otra óptica, marcada por la propia realidad rural. Las diferencias entre unos y otros se han investigado con anterioridad, indicando la conveniencia de que los docentes transiten por la experiencia de la escuela rural como parte integral de su proceso de formación profesional y de la consolidación de su identidad gremial. El maestro educa al rancho, pero también el rancho educa al maestro.

\section{LOS ESPACIOS ESCOLARES, HOY}

Los gritos de docentes y estudiantes se han cancelado en los espacios escolares que estudiamos. Sus aulas, si siguen en pie, permanecen polvorientas y con los cristales estrellados. Las escuelas que en otro tiempo rebosaban actividad, hoy son espacios mudos, guardianes de recuerdos y añoranzas. En algunos casos la escuela original se ha caído, o derruido. En ninguna comunidad se implementaron estrategias de mantenimiento y conservación sistemática de los espacios escolares desde las autoridades, ni de las propias comunidades. El tiempo ha hecho lo suyo, y los recuerdos nostálgicos y las añoranzas de quienes fueron sus alumnas y 
alumnos no son suficientes para tapar las goteras en las casas del maestro ni para remendar los huecos en los cercos de adobe, por donde tranquilas se cuelan las vacas, a pastar junto al astabandera desnuda y rebelde.

En algunas comunidades la escuela se utiliza hoy como espacio para los servicios del Consejo Nacional de Fomento Educativo (CONAFE), o como dispensario médico, o como almacén para usos diversos de la autoridad ejidal. Sin embargo, estos casos son los menos comunes. En la mayor parte de las rancherías las escuelas se quedaron abandonadas, mirando hacia el camino de tierra por donde supuestamente llegarían los funcionarios del gobierno estatal con nuevas ideas y nuevos proyectos para inyectarles vida. Ha pasado ya casi un cuarto de siglo, y las escuelas siguen esperando. Resulta inevitable sentir la emoción de la vocación educativa que alguna vez, durante décadas, tuvieron esas tapias y esos mesabancos hoy desvencijados, y lamentar la ausencia de programas oficiales o comunitarios de rescate de sus espacios, y sobre todo de los archivos escolares, tan valiosos para la historia de cada ranchería y de cada niño y niña que transitó por sus salones de clase.

Ilustración 19. Exterior de la primaria. La Selva

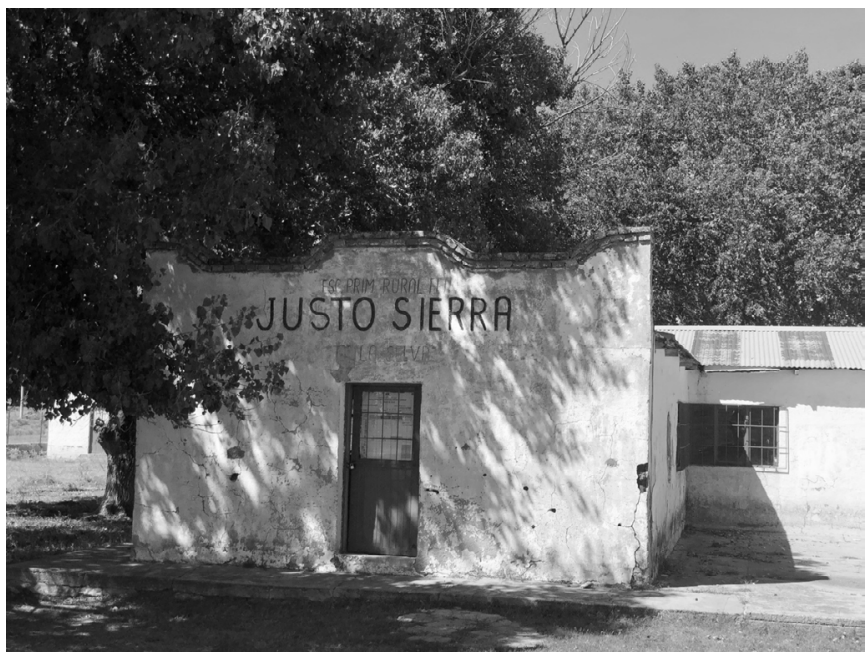


La escuela pública, rural, percibida por la comunidad como un bien comunitario y compartido debe mantenerse. Su aportación a la vida rural, y su contribución a la elevación de la calidad de vida de las familias que atiende es invaluable e irremplazable. Por ello debe impulsarse el interés por preservarla desde las comunidades, pero sobre todo desde las instancias educativas oficiales.

Los edificios escolares en los ranchos estudiados, con sus recuerdos, con sus risas ahogadas en el tiempo, con sus graduaciones de tres horas, se derriten aún en la canícula de julio, o aprietan los ojos de terrado, y aguantan los ventarrones de febrero, pero la expectativa de preservación de sus contenidos es baja. Los archivos escolares que contienen, así como el menaje de las aulas, los materiales para enseñar, la dimensión tangible de la institución escolar, desaparecerán irremediablemente en los años cercanos.

Ilustración 20. Patio escolar. La Selva

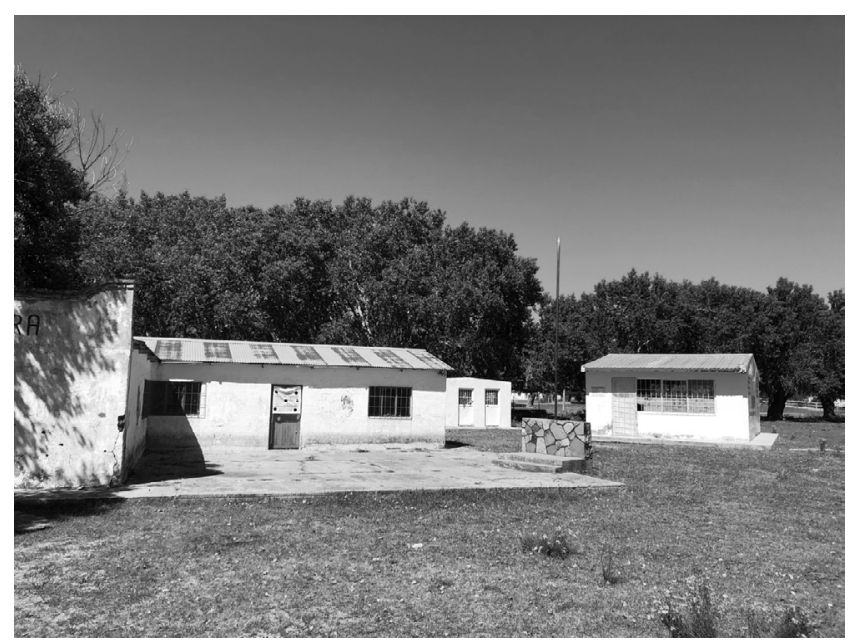

REFLEXIONES FINALES

Los aprendizajes construidos a través de nuestro acercamiento a las escuelas abandonadas en la región de Cuauhtémoc son congruentes con los objetivos de nuestro proyecto de investigación. 
El ejercicio hizo posible construir una mirada compleja de sus realidades y procesos antes de su cierre definitivo.

Más allá, el colofón de las reflexiones emprendidas a partir de este proyecto es que el tema de los centros educativos abandonados en 1997 representa una oportunidad para las autoridades educativas -federales, estatales, de los municipios-, pero sobre todo para las comunidades y sus habitantes. Esta oportunidad consiste en el rescate de la propia historia de la comunidad, y del aprovechamiento de los espacios escolares olvidados para propósitos compartidos. Esto debe ocurrir pronto, antes de que lo que queda de las antiguas escuelas se derrumbe por completo, como ya ha ocurrido en varias localidades.

Las escuelas cerradas también están a la espera de los historiadores de la educación, de los estudiosos de los procesos educativos, para que se maravillen con las historias contenidas en los expedientes escolares, para que desempolven las colecciones fotográficas -verdaderos tesoros- y miren a los ojos a los protagonistas de las historias de otros tiempos, los mismos ojos, los mismos niños y niñas, los mismos maestros y maestras... Esta añoranza es, desde nuestra perspectiva, la más importante en las condiciones actuales. Surge en primer lugar la necesidad de rescatar los archivos escolares, sistematizarlos y aprovechar su información para la construcción de la microhistoria de esa constelación de comunidades rurales

Otra vertiente prometedora de investigación, también a la espera de ser explotada por académicos y académicas interesadas, es el rescate de la historia oral de estos espacios a través de las memorias de aquellos que pasaron por las aulas y los patios de estos centros escolares. En cada rancho viven aún los alumnos y alumnas de la escuela rural, cada uno con su costal de anécdotas, con sus certificados de primaria empolvados, colgados en la misma pared desde hace cuarenta años y con dos o tres fotografías de la graduación, del concurso de oratoria, de la ronda, del festival del día de las madres.

Queda además pendiente, como dijimos ya, la tarea de en la medida de lo posible rescatar los inmuebles escolares, que cons- 
tituyen puntos neurales de la distribución espacial del rancho, y de las cargas simbólicas de la comunidad. En todos los casos la escuela está situada físicamente en el centro de la ranchería, o en un espacio privilegiado de la misma. Esto significa oportunidades importantes para la promoción de la restauración de sus antiguos edificios y para el impulso de su utilización como centros comunitarios, talleres del rancho, espacios para la celebración de asambleas y fiestas rancheras; como escenarios de la celebración de nuevos torneos deportivos y culturales, o como espacios para la preservación de la memoria compartida.

La vuelta al modelo de la constelación de escuelas rurales se ha ido para no volver, por razones económicas, políticas y desde luego demográficas, pero dejó tras de sí todas estas tapias, cargadas de recuerdos, de añoranzas y de posibilidades para repensar su sentido en el contexto de la comunidad rural chihuahuense del siglo XXI, marcada por nuevos desafíos y nuevas exigencias. En este panorama, sin duda las antiguas instalaciones escolares pueden recargarse de sentido y jugar un nuevo papel en las comunidades que las acogen.

En el contexto de estos nuevos escenarios, marcados por la inmediatez, la crisis identitaria y los problemas sociales, hoy nos planteamos una pregunta clave: ¿Cómo debe ser la escuela del siglo XXI, para responder de forma efectiva a las expectativas que la sociedad tiene de ella? En muchos sentidos, en las tapias de las antiguas escuelas está la respuesta a esta y otras preguntas de la escuela pública y de la sociedad chihuahuense de estos nuevos tiempos. 


\section{Ilustración 21. Cancha deportiva. La Selva}

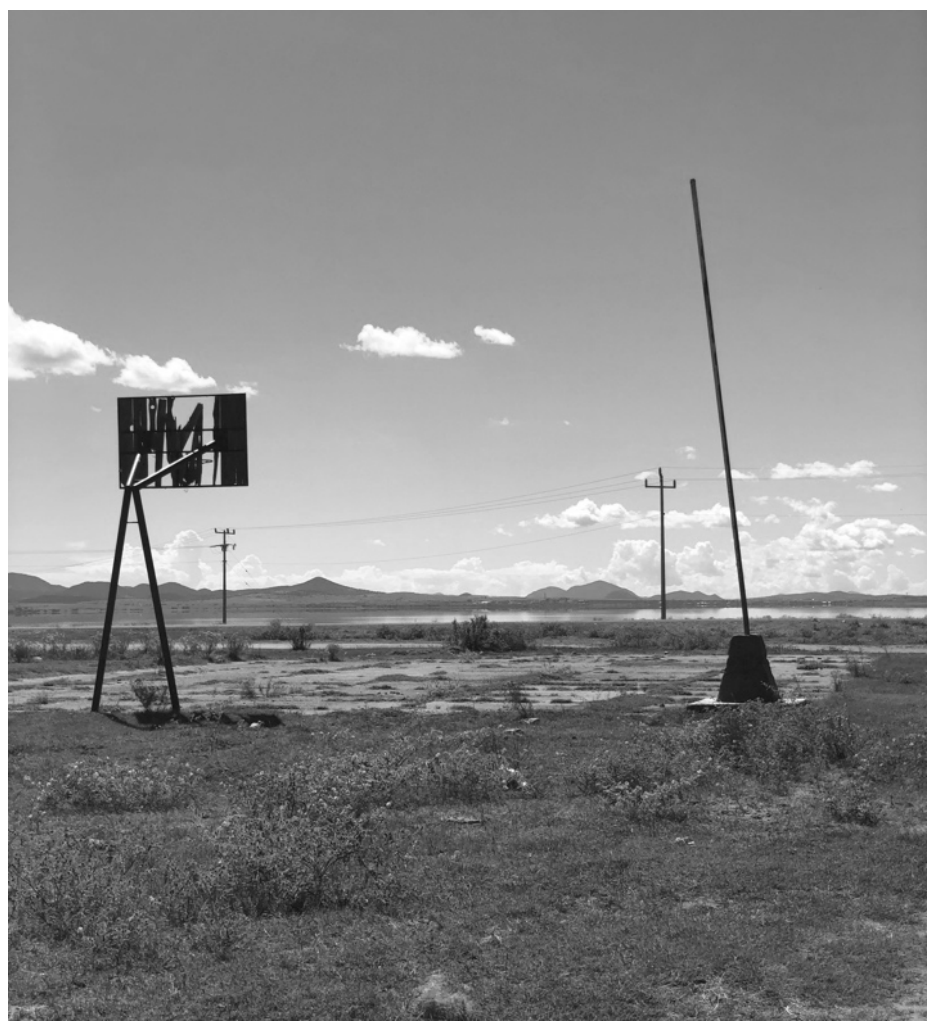

TRABAJOS CITADOS

Brumat, M. R. (2011). Maestros rurales: condiciones de trabajo, formación docente y práctica cotidiana. Recuperado el 6 de abril de 2019, de https://dialnet.unirioja.es/servlet/ articulo?codigo $=3688179$.

Castro Martínez, P. (1999). Ciudad Cuauhtémoc, Chihuahua: un fruto social de la Revolución mexicana. Recuperado el 3 de octubre de 2018, de http://polismexico.izt.uam.mx/index.php/ rp/article/view/370/0.

Centro piloto PIRE. (2009). Proyecto: café con aroma de corridos para una lectura presente. En P. E. Completo, Buenas prácti- 
cas educativas en la jornada escolar ampliada (Vol. 2, págs. 50-59). México: Secretaría de Educación Pública.

Cordero Arroyo, G., Serrano, E. L., y Patiño Alonso, N. X. (2011).

"La profesionalización de los maestros de educación básica.

Retos para las instituciones de educación superior". Perfiles Educativos, 33, 239-249.

Informante 2, T. L. (2018). Entrevista sobre escuelas abandonadas.

(F. Sandoval Gutiérrez, Entrevistador).

Glaser, B., y Strauss, A. (1967). The discovery of grounded theory: strategies for qualitative research. New Brunswick: Aldline.

Guillén Añorve, M. A. (1991). "La fiabilidad en la entrevista: la entrevista semiestructurada y estructurada, un recurso de la encuesta”. Investigación Bibliotecológica, 5(010).

Gobierno del Estado de Chihuahua (2016). Programa sectorial. Secretaría de Economía. Chihuahua: Gobierno del Estado de Chihuahua.

Larios Guzmán, M. E. y Hernández Orozco, G. (2012). Desempeño y profesionalización: las maestras de párvulos, en la historia de la educación en Chihuahua, México, durante las primeras décadas del siglo XX. Recuperado el 5 de abril de 2019, de http://investigaciones.uniatlantico.edu.co/revistas/index.php/ historia_caribe/article/view/810.

Loera Palma, M. A. (2007). Centros Regionales de Educación Integral CREI. Actas del primer encuentro de ex becarios del IFP México. México: Ford Foundation. Obtenido de Programa Internacional de Becas de Posgrado para Indígenas: http://ford. ciesas.edu.mx/.

Martínez Rizo, F. (2012). Varios miles de millones de libros. Recuperado el 6 de abril de 2019, de http://scielo.org.mx/pdf/rmie/ v17n54/v17n54a14.pdf.

Mancera Valencia, F. J. (2014). Educación patrimonial en comunidades rurales del Estado de Chihuahua, México. Recuperado el 6 de abril de 2019, de https://dialnet.unirioja.es/descarga/ articulo/5385931.pdf. 
Ortiz Franco, P. y Amado Alvarez, J. P. (2001). "Uso del agua de la laguna de Bustillos para la producción de maíz”. Terra Latinoamericana, 19(2), 183-189.

Pacheco, L. C. (2013). Fuimos a sembrar cultura: los maestros y la construcción de la escuela rural mexicana. Recuperado el 6 de abril de 2019, de http://132.248.9.34/hevila/investigacionypostgrado/2013/vol28/no1/3.pdf.

Peiró i Gregòri, S. (2008). Cultura, valores y educación. Recuperado el 5 de abril de 2019, de https://rua.ua.es/dspace/handle/10045/8735.

Ramírez Arias, L. (2016). Aportes de una radio comunitaria al desarrollo rural. Recuperado el 6 de abril de 2019, de https:// repository.javeriana.edu.co/handle/10554/21105

Sandoval Gutiérrez, F. (2014). “Alternancia política y educación. La realidad educativa en Chihuahua durante el primer gobierno de alternancia”. Historia Caribe, 215-239.

Vera-Bachmann, D., \& Salvo, S. (2016). "Cierre de escuelas rurales y salud colectiva”. Salud Pública de México, 58(1), 4-5. 